\section{Estudio histórico-estratigráfico de los muros de la nave central de la catedral de Teruel y su encuentro con la techumbre}

\section{Historical and stratigraphical study of the walls of the main aisle of the Cathedral of Teruel and their joints with the roof}

Berta de Miguel Alcalá

Arquitecto técnico. Máster en Conservación del Patrimonio Arquitectónico.

Gabriel Pardo Redondo*

Ingeniero de edificación. Máster en Conservación del Patrimonio Arquitectónico.

\section{Resumen}

Datada entre finales del siglo xII y comienzos del XIII, la Catedral de Teruel es un edificio complejo cuyo destacado tesoro es la techumbre mudéjar que cubre la nave central, declarada Patrimonio Mundial en 1986 por la UNESCO'. De esta magnífica obra de madera policromada se desconocen aspectos tan elementales como quién la construyó, cuándo, cómo y qué representa. Son muchas las teorías que pretenden dilucidar tales incertidumbres y poca la documentación histórica de que se dispone. Durante los años 2008 y 2009, se acometió una restauración que dejó al descubierto parte de la armadura de la cubierta y de los muros que la sustentan. Aprovechando la eliminación temporal de los revestimientos exteriores, se desarrolló un extenso trabajo de análisis estratigráfico y constructivo de los muros de la nave central y de su encuentro con la armadura. Dicho trabajo arroja resultados en torno a las modo, se aportan evidencias que suponen un importante avance en el conocimiento de la fisonomía de la iglesia en sus primeras etapas.

Palabras clave: Tapia de yeso, estratigrafía muraria, arquitectura mudéjar, policromía mudéjar, armadura de madera, fotogrametría, proceso histórico-constructivo. intervenciones llevadas a cabo durante la vida del templo. Del mismo

\section{INTRODUCCIÓN}

Turboleta, Turiolis, Tirwal $^{2}$...Teruel. Existen indicios de asentamiento humano donde se ubica la actual Teruel ya en época Íbera; se trataba de un núcleo de poca entidad hasta la fundación de la ciudad por Alfonso II en 1177. A 915 metros de altitud, la ciudad se encuentra en posición estratégica en las comunicaciones entre el litoral mediterráneo y el interior de la Península Ibérica.

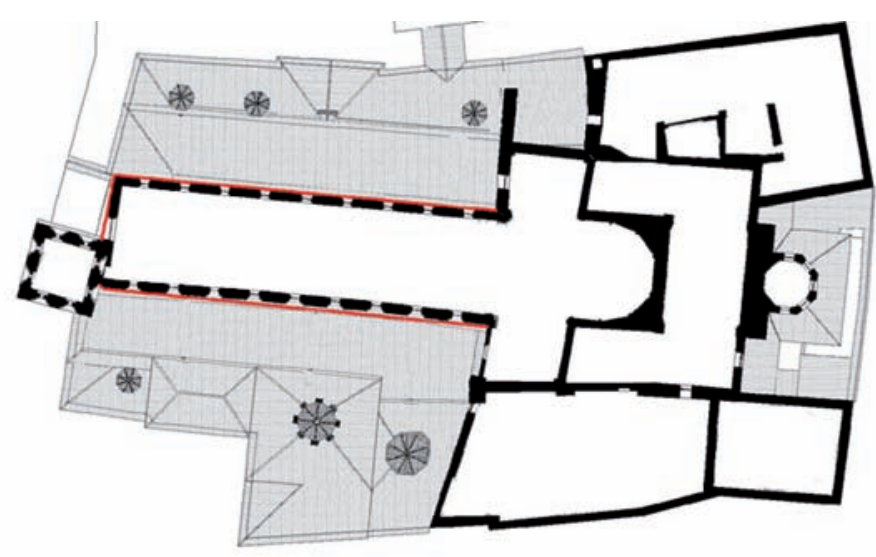

Fig. 1. Planta de la catedral. En rojo, los muros estudiados

La Catedral de Santa María de Mediavilla se ubica en el centro de la población; se trata de un edificio complejo fruto de innumerables intervenciones de remodelación, ampliación y trasformación. De planta rectangular, se compone de tres naves siendo la central la más elevada, cubierta por una magnífica techumbre mudéjar. Las latera-

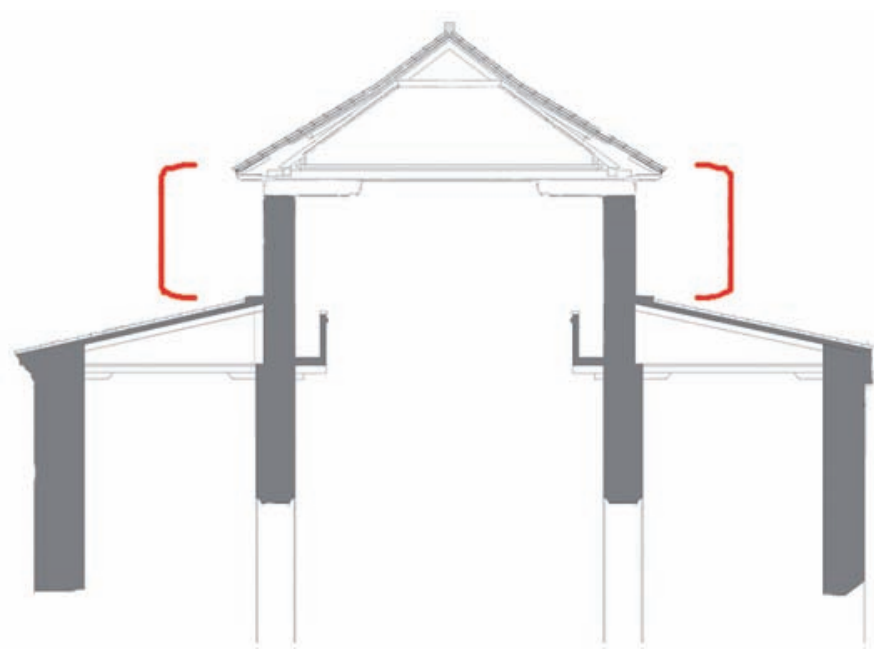

Fig. 2. Sección de la catedral. En rojo, los muros estudiados

* bertarqtec@hotmail.com; gpredondo@hotmail.com

${ }^{1}$ Inicialmente, en 1986, formó parte de una declaración colectiva denominada "Arquitectura Mudéjar de Teruel» que en 2001 fue ampliada a "Mudéjar de Aragón».

\section{Abstract}

Dated to late 12th and early 13th centuries, the Cathedral of Teruel is (n) who built it, how, when or what it represents. There are many much historical documentation available. During the years 2008 and discovered concerning the modifications suffered by the building. At the same time, other evidences help to further going within the Keywords: Gypsum walls, wall stratigraphy, Mudejar architecture, Mudejar polychromy, timber roof, photogrammetry, historicalconstructive process.
${ }^{2}$ Turboleta, Turiolis, Tirwal. Denominación de Teruel en época íbera, romana y musulmana, respectivamente. 


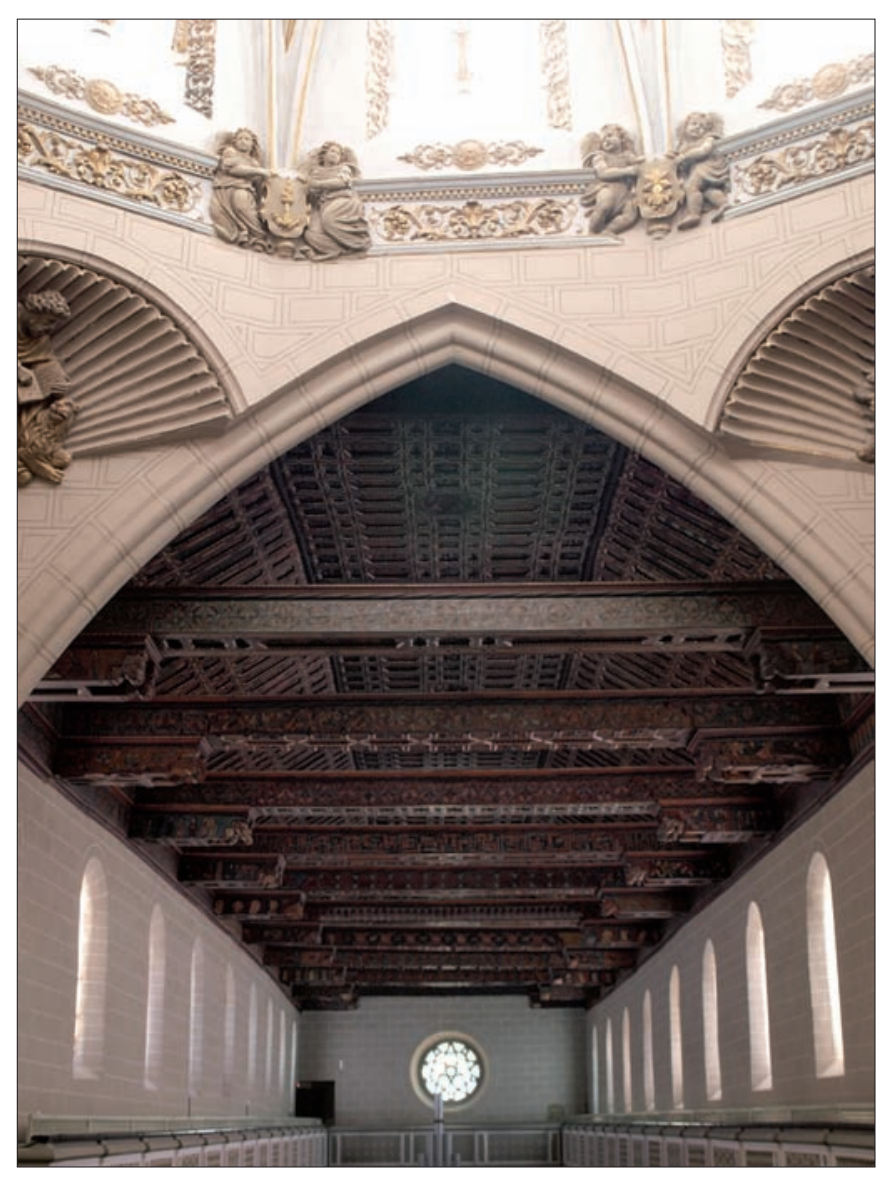

Fig. 3. Vista general interior de la techumbre desde el presbiterio

les se cubren con sendos alfarjes de mediados del siglo XX. El ábside, heptagonal, está circundado por una girola desde la que se accede a sacristías, archivos y salones parroquiales. Alrededor de todo este conjunto se distribuyen un total de nueve capillas. Cada muro longitudinal (norte y sur) de la nave central consta de nueve ventanas de arco de medio punto. El muro hastial (oeste) de $5.91 \mathrm{~m}$ de longitud, no cubre por completo la anchura de la nave debido a su intersección con la torre-campanario y presenta un óculo alineado con el eje de la nave principal.

Según Yarza, en Borrás (1999), el campanario data de 1257 y se considera el último elemento construido de la primitiva iglesia románica. En 1537 se construyó el actual cimborrio mudéjar y en torno a 1700 las bóvedas que ocultarían la techumbre hasta que una bomba caída durante la Guerra Civil la dejase al descubierto; aunque oculta, siempre se supo de su existencia.

El presente artículo resume el estudio vinculado a la lectura directa de la parte superior de los muros de la nave central por su cara externa (figs. 1 y 2) y su encuentro con la techumbre; el estudio se estructuró alrededor de un análisis estratigráfico-constructivo y una posterior inter- pretación de los datos, contrastándolos con las fuentes históricas.

\section{ANTECEDENTES}

La primera referencia arquitectónica escrita de la entonces Iglesia de Santa María de Mediavilla data de 1232; se encuentra recogida en una serie de pergaminos del Archivo de la Catedral de Teruel y trata de obras de pequeña entidad ${ }^{3}$.

En 1870 Blasco y Val ${ }^{4}$ describió el edificio, destacando que "la nave central y el trasaltar han sido renovados de arquitectura moderna siendo muy regular el techo de de las naves laterales).

En 1904, Pano y Ruata planteó la hipótesis de que la primitiva iglesia consistía en una única nave con ábside, sin certeza de si la torre situada a los pies del templo fue anterior o contemporánea. Mediante comparación con la techumbre del monasterio de Sijena, dató la de Teruel a comienzos del siglo XV. Tres años más tarde, el Marqués de Monsalud (1907) presentó un informe en el que recogía un manuscrito de 1335 donde aparecían todas las cuentas realizadas en el transcurso de las obras llevadas a cabo en esos años.

Siguiendo la misma línea que Pano y Ruata, en 1909 Cabré reforzó la teoría de la primitiva iglesia de única nave de igual anchura y longitud que la actual. En cambio dató la techumbre sobre la segunda mitad del siglo XIII así como la torre mudéjar, basándose en el manuscrito mencionado anteriormente. Cabré es el primero que destacó las magnificas policromías en los aleros de la nave central citando «es de tanto admirar como el soberbio artesonado». También estableció que las naves laterales se realizaron en torno al año 1577 cuando el templo, por entonces colegiata, fue elevado al rango catedralicio. Él defendió que las nuevas naves se cubrirían con bóvedas de crucería, lo que provocaría empujes horizontales en las pilastras de la nave central, generando considerables perjuicios en la estructura, los cuales serían solucionados más de 100 años después, en 1685, contrarrestando los empujes con la construcción de bóvedas en la nave central.

Una vez pasada la Guerra Civil Española, durante la que la catedral fue gravemente dañada, se llevaron a cabo una serie de reconstrucciones y obras de recuperación. Es entonces cuando se desvelaron muchos datos que hasta la fecha quedaban ocultos. Expertos en arquitectura e investigación histórica como Torres Balbás (1953), Navarro

\footnotetext{
${ }^{3}$ Tomás Laguía, 1953: p. 15.

${ }^{4}$ Blasco y Val, 1870: pp. 119-129.
} 


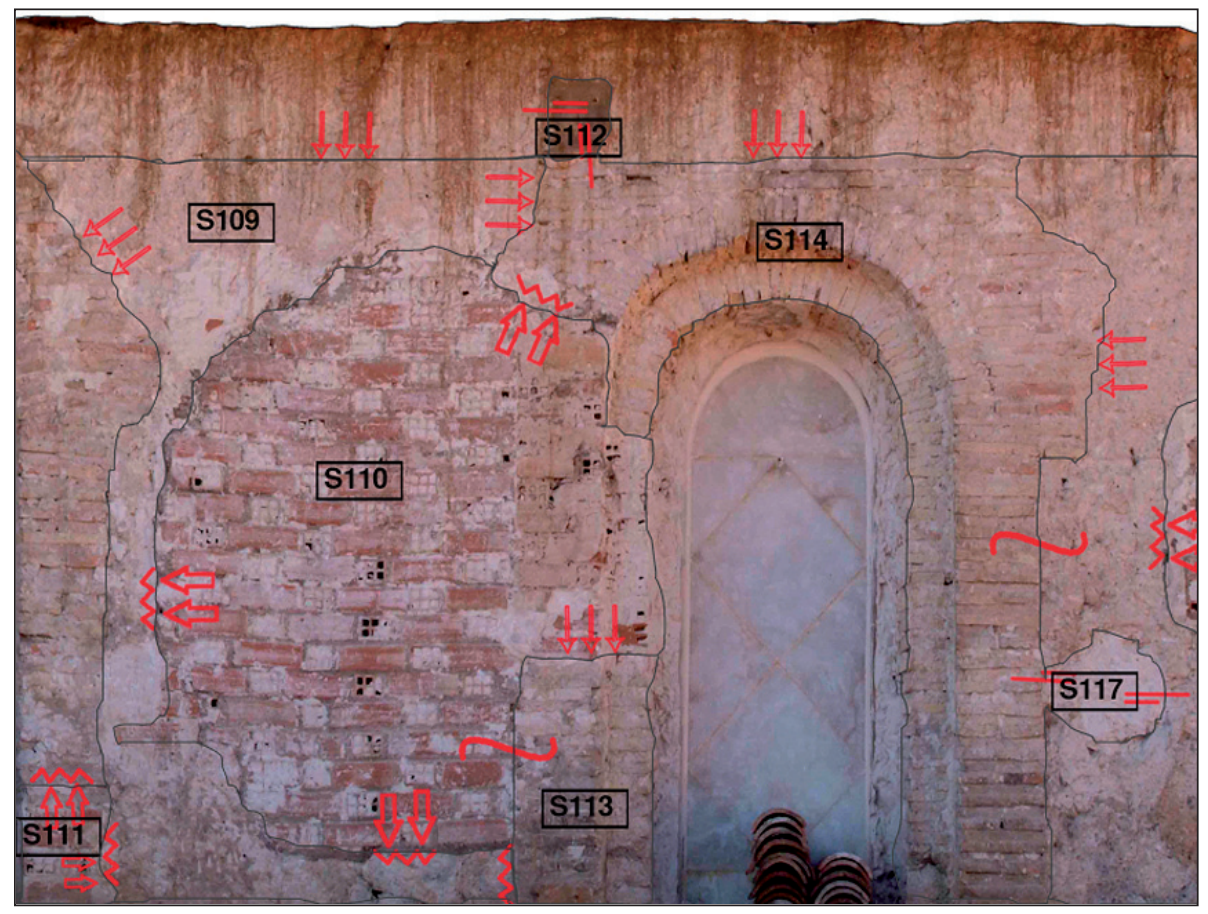

Fig. 4. Estudio estratigráfico de una zona del muro sur

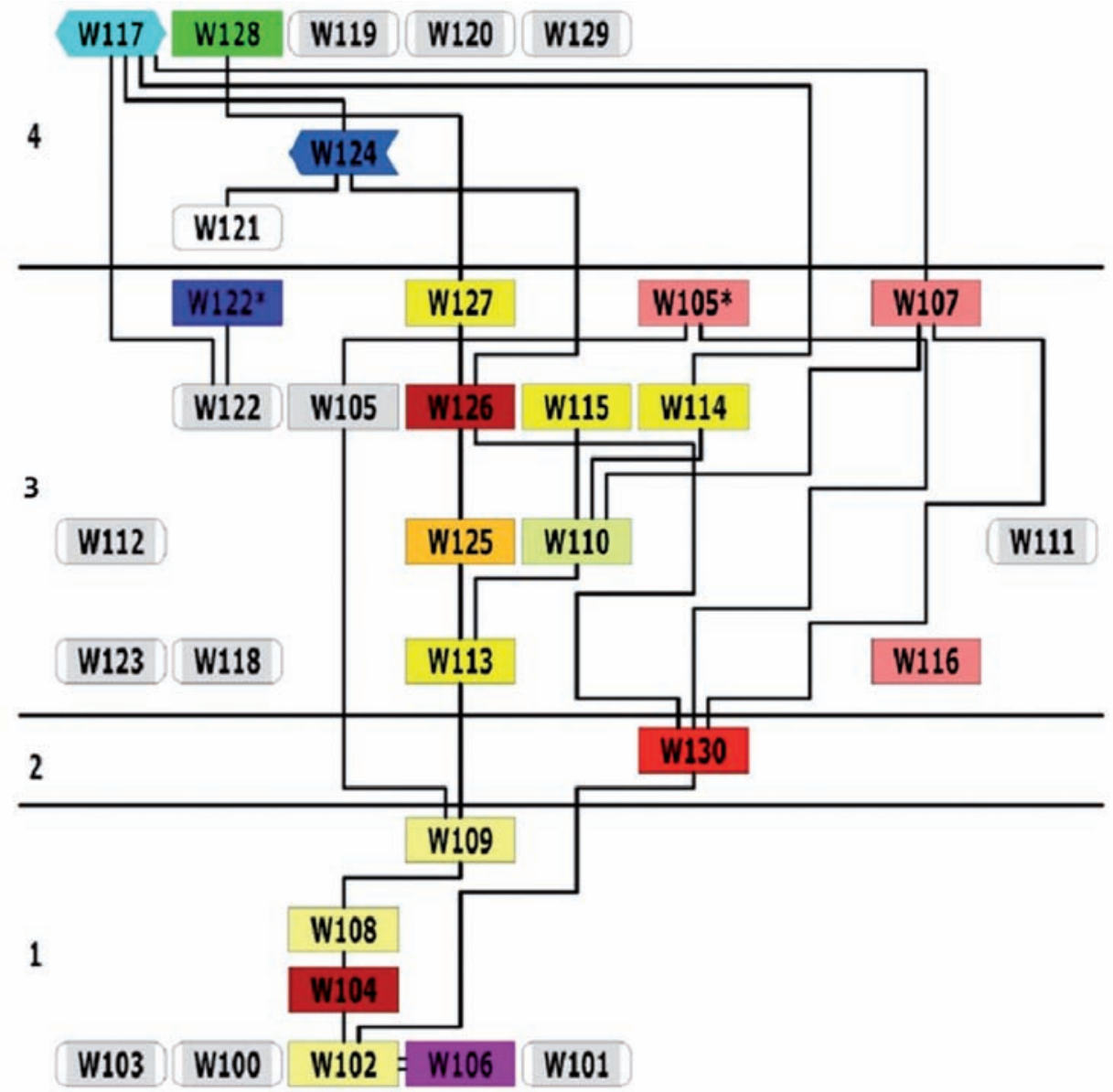

Fig. 5. Diagrama de Harris por periodos, fachada oeste 
(1953), Novella (1999) o Yarza (1981), entre otros, abordaron el estudio de la catedral.

La teoría de la primitiva iglesia con única nave fue desestimada por Navarro (1953), que estableció que la iglesia contaba con tres naves con sus respectivos ábsides y techumbre de madera. A su juicio, la sobreelevación de los muros sería realizada en el siglo XIV sustituyendo la techumbre existente por la actual. El orden de ejecución de esta nueva reconstrucción, según Torres Balbás (1953), fue progresiva torre-cuerpo-cabecera y además se engrosarían los pilares de la nave central.

Gracias a las visitas durante las obras llevadas a cabo en el siglo XX, Novella pudo registrar vestigios de ventanas, aleros y otros elementos de fases anteriores embebidos ahora por las ampliaciones del templo. Así pues, él dató la primera iglesia en torno al año 1200 y la sobreelevación de los muros en la segunda mitad del siglo XIII, terminando esta etapa en 1335 con el enlucido y decoración del crucero.

Ya, a finales de siglo XX, se realizaron varios estudios científicos como el análisis dendrocronológico realizado en 1991, por el cual se determinó el corte de las maderas que forman la techumbre en $1261^{5}$.

De época más reciente es el completo informe arqueológico de Ibáñez (2002) del Plan Director de la Catedral de Teruel, donde se recogieron las últimas intervenciones y hallazgos. Destaca el descubrimiento de cimientos, al parecer de origen románico, en el lugar que ocuparían los ábsides de las naves laterales, reforzando así la teoría establecida por Novella (1999) y Navarro (1953). No se encontraron indicios de ningún asentamiento previo por lo que estableció la creación de la primera iglesia en el año 1177 , año de fundación de la villa, posteriormente sobreelevada a mediados del siglo XIII; fijó la realización de la techumbre en una fecha anterior a 1335. Ibáñez enfatizó la importancia arqueológica que tiene el muro oeste a los pies de la nave central considerándolo " la estructura que se conserva visible más antigua de todo el conjunto y de la ciudad de Teruels.

\section{ESTUDIO ESTRATIGRÁFICO}

En primer lugar se procedió a la lectura directa de los muros, consistente en identificar, según los criterios de la estratigrafía muraria ${ }^{6}$, los diferentes estratos, definiendo sus contornos, anotando las relaciones de temporalidad entre ellos y registrando sus características (materiales

\footnotetext{
${ }^{5}$ Almagro, 1991: p. 190. Se trata de una información verbal proporcionada por Eduardo Rodriguez Trobajo, autor de la datación dendrocronológica.

${ }^{6}$ Mileto, 2000.
}

utilizados, técnica constructiva, color, texturas, composición, acabado superficial,...). En la lectura llevada a cabo se encontraron variedad de fábricas de distinta naturaleza (tapias de yeso, fábrica de ladrillo mudéjar...), varios revestimientos (liso, esgrafiado...), roturas del muro, etc. (figs. 4 y 6).

Una vez analizada la información de los estratos, se realizó una clasificación de éstos mediante fichas estratigráficas donde se recogían parámetros y características como nombre, tipo de fábrica, ubicación, relaciones estratigráficas, interpretación e hipótesis de periodo y fase a la que pertenecían. Todo ello con el fin de generar una base de datos capaz de sintetizar toda la información.

La última etapa del estudio estratigráfico fue la realización de un diagrama cronológico (método de Harris, 1991) en el que se recogieran gráficamente las relaciones de anterioridad, posterioridad y contemporaneidad de los diferentes estratos. La característica que se ha añadido al diagrama ha sido la introducción de colores y formas con la finalidad de aportar mayor información del estrato y permitir al lector comprender el esquema de un modo más visual (fig. 5).

Según el diagrama de Harris se distinguen cuatro periodos de ejecución en los tres muros estudiados, los cuales coinciden con los datos históricos encontrados.

\section{ESTUDIO CONSTRUCTIVO}

\section{Muros}

Dada la peculiaridad del principal componente, yeso obtenido de las proximidades de Teruel, y tras averiguar que los muros estaban realizados con la técnica del tapial, se realizó un estudio y análisis de esta técnica constructiva, consultando bibliografía técnica tradicional y estudios recientes ${ }^{7}$. Las conclusiones fueron sorprendentes, ya que los muros están realizados con una argamasa de yeso con piedras de pequeño tamaño y con mampuestos de piedra en el interior del muro. La masa se introducía en el cajón o tapial como si se tratara de un hormigón actual, pero una vez vertido el compuesto no se apisonaba de la misma manera que las tapias de tierra, aportando un característico aspecto exterior.

Los muros longitudinales de la nave central combinan la fábrica de tapia con machones de fábrica de ladrillo macizo que conforman las jambas de sus ventanas, colocados a soga y tizón alternando hiladas, y a rosca en el arco de medio punto. Se comprobó, que el aparejo del intradós se

Cristini, Mileto y Vegas, 2009: pp. 99-108. 


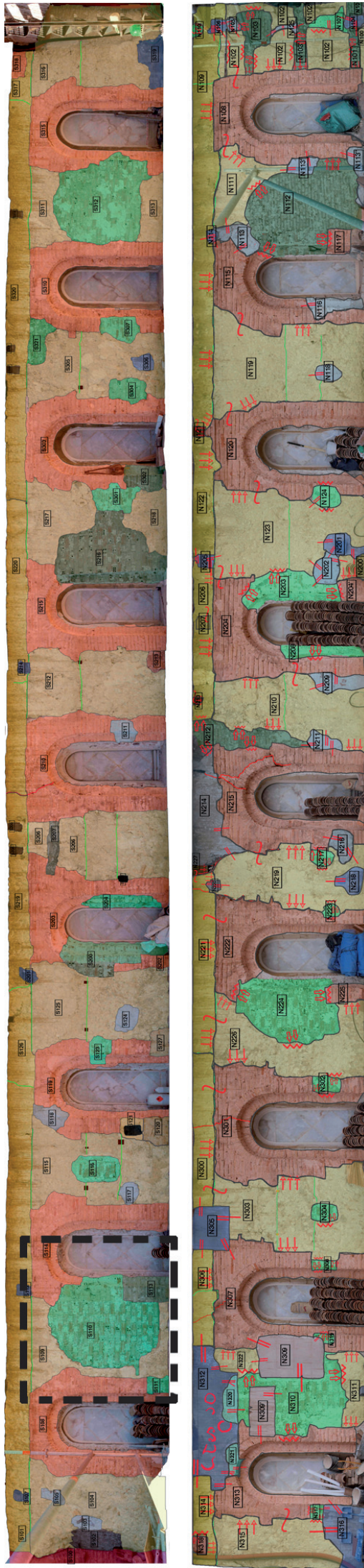

Fig. 6. Estatigrafía. Tipos de fábricas en el muro sur (arriba) y norte (abajo). Recuadro ampliado en figura 4 ejecutó mediante fábrica de ladrillo macizo colocado a soga, con idénticas dimensiones que los encontrados en el exterior y con la habitual junta matada superiormente utilizada en la arquitectura mudéjar. Tras un minucioso análisis del muro se descubrió, gracias a la disposición de los ladrillos que conforman los machones de las ventanas, cuál había sido el sistema de ejecución con el que se erguían estos peculiares muros. En primer lugar, se levantaba la fábrica de ladrillo hasta una determinada altura (entre 70 y $90 \mathrm{~cm}$ ), conformando las jambas de las ventanas. Entre la jamba de una ventana y la jamba de la contigua se encofraba y se vertía el «hormigón de yeso» hasta la altura de la fábrica de ladrillo. El proceso se repetía de igual manera por hiladas horizontales en ambos muros longitudinales. Debido a que el interior del templo se encuentra enlucido en la actualidad, no se pudo investigar cómo se combina la fábrica de ladrillo del intradós, aunque todo apunta a que se levantaba a la vez que el muro, sirviendo de encofrado perdido y trabándose con los machones de las ventanas (ver fig. 28).

A diferencia de los muros longitudinales, el muro hastial se compone única y exclusivamente de tapia de yeso por su cara externa (a excepción del zócalo de piedra), distinguiendo claramente la altura de las tapias que varían entre los 90 y los $98 \mathrm{~cm}$. Se hallaron restos de un gran óculo circular, de 3,13 m de diámetro, realizado en la fábrica de tapia. La característica más sorprendente de este óculo es que está conformado únicamente con la propia fábrica de tapial. Para ejecutar este elemento, se previeron unos agujeros pasantes en el muro para sustentar una plataforma de trabajo; a partir de aquí se contemplan dos posibilidades: el óculo se podría haber realizado a la vez que se levantaba el muro, lo cual requeriría de un encofrado de dimensiones considerables; o bien, el óculo se realizó con una técnica que consistía en ejecutar el muro continuo $y$, posteriormente, desde la plataforma, picarlo hasta conformar el óculo. En este muro también se encontraron otros elementos como agujas originales y huellas relevantes para el análisis de su ejecución, así como para su datación. La impronta más interesante tiene forma alargada rectangular colocada en posición vertical con una altura de 94 $\mathrm{cm}$, coincidente con una tapiada, y se sitúa a escasos centímetros del cuerpo del campanario. Esta huella corresponde a un elemento auxiliar del encofrado, el barzón, que se utilizaba en la técnica de tapial cuando el muro interseccionaba con otro elemento; este hallazgo puede implicar la existencia de una construcción en la posición del actual campanario en el momento de ejecución del muro. 


\section{Armadura de cubierta}

La armadura que descansa en estos muros, responde al modelo de par y nudillo sin hilera, con tirantes pareados sobre ménsulas que dividen la nave longitudinalmente en nueve tramos. Las mismas piezas, totalmente ornamentadas en su intradós, cumplen la función estructural. Está formada por 80 armazones verticales, compuestos por pares de 10 a $12 \mathrm{~cm}$ de anchura, cuyos ejes distan $39 \mathrm{~cm}$. Cubren una longitud aproximada de $31 \mathrm{~m}$. Los nudillos forman el plano del almizate, el harneruelo. Los pares o alfardas forman los faldones inclinados. La luz es de 7,70 $\mathrm{m}$ en el centro de la nave. Los muros sobre los que se apoya son de tapia de yeso y tienen una media de $80 \mathrm{~cm}$ de espesor. Desde el almizate hasta la cara inferior del encuentro entre pares de cada armazón, hay una altura de 1,20 m. Los canecillos del alero, 84 en el lado sur (Epístola), 86 en el lado sur (Evangelio) y 16 en el hastial, vuelan $70 \mathrm{~cm}$ y se empotran aproximadamente la misma longitud en el muro.

La obra acometida en los aleros durante los años 2008-2009 comprendía la retirada de la teja en toda la cubierta, el levantado del tablero bajo teja, sólo en la zona del encuentro de la armadura con el muro ( $2 \mathrm{~m}$ aproximadamente), y la restauración o reposición de los elementos líg-

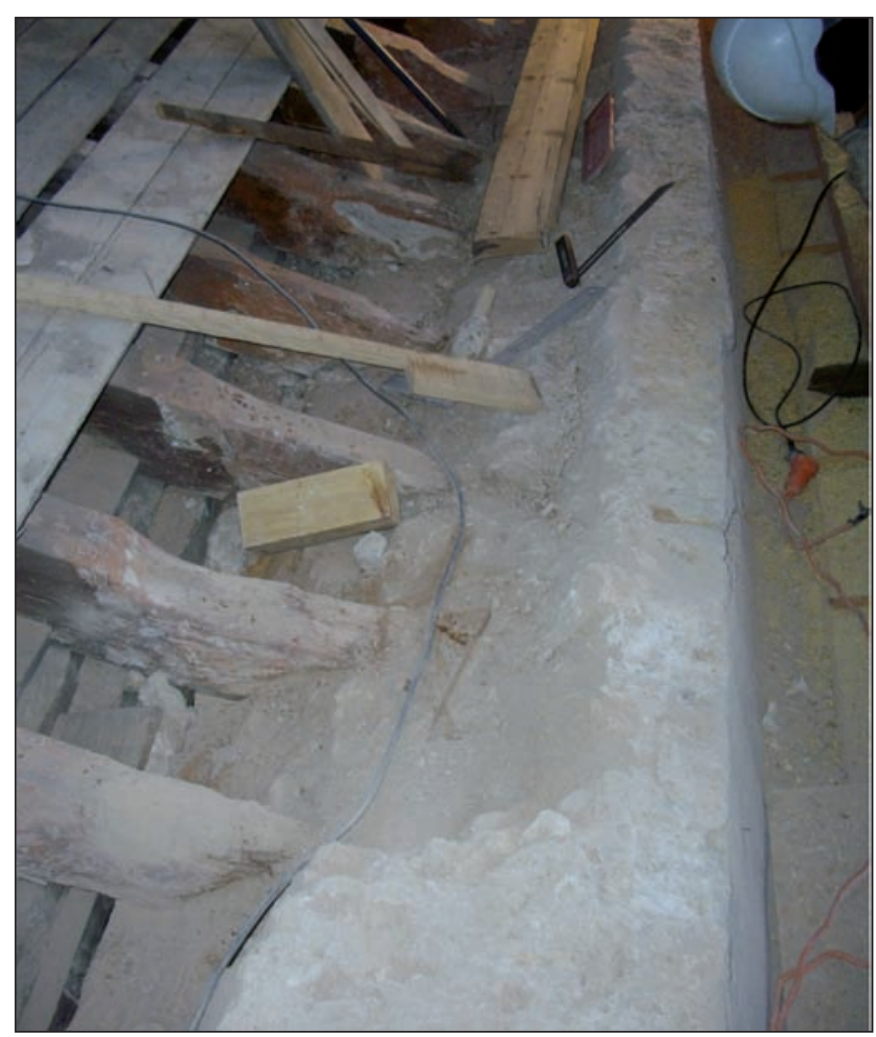

Fig. 7. Coronación inclinada del muro de tapial que maciza los encuentros de la armadura con el muro

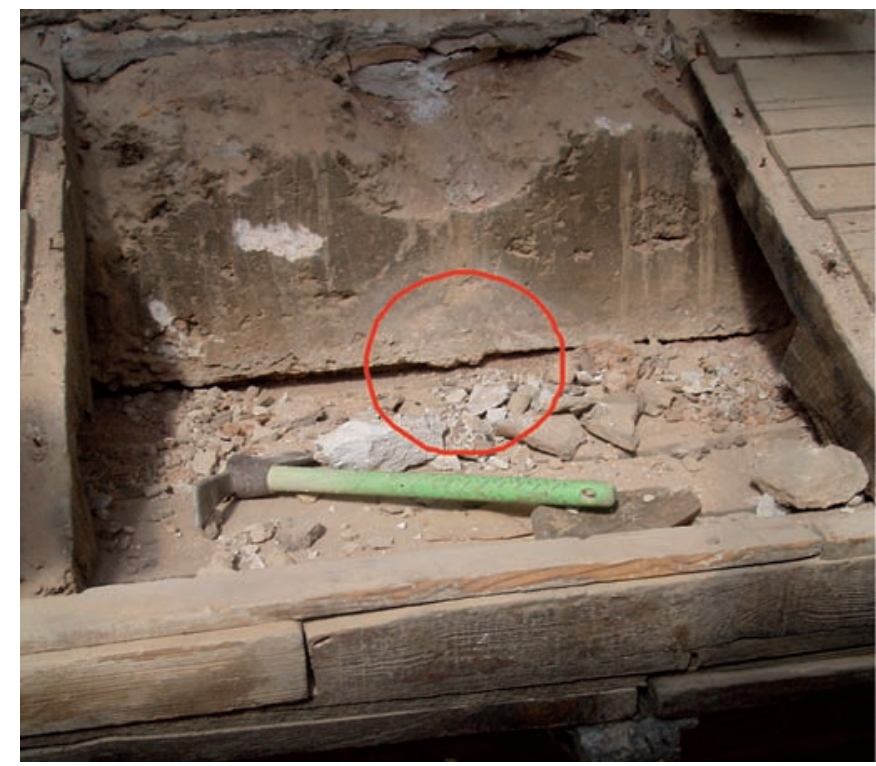

Fig. 8. Improntas de elementos perdidos. En el interior del círculo se aprecia el encuentro entre dos tablas menadas

neos deteriorados, así como la recuperación de las policromías de los aleros. Una vez levantado el tablero sobre el que descansaba la teja, apareció un relleno sobre el encuentro de la armadura coincidente en planta con el muro (fig. 7). Se tenía constancia de su existencia, si bien se había considerado, hasta ese momento, que había sido ejecutado por el Servicio de Regiones Devastadas en los años 40. Se comprobó in situ que esa afirmación era errónea. En primer lugar, el material empleado era el mismo que el que se utilizó en su día en la confección de los muros sobre los que se apoya, tapia de yeso. En segundo lugar, dicho relleno conserva improntas de elementos de la armadura perdidos antes de la contienda civil, como las tablas menadas o la cabeza de los saetinos (fig. 8).

En la coronación del muro se midieron los elementos lígneos, comprobando que existe un espacio vertical entre los canecillos y el estribo de aproximadamente $12 \mathrm{~cm}$,

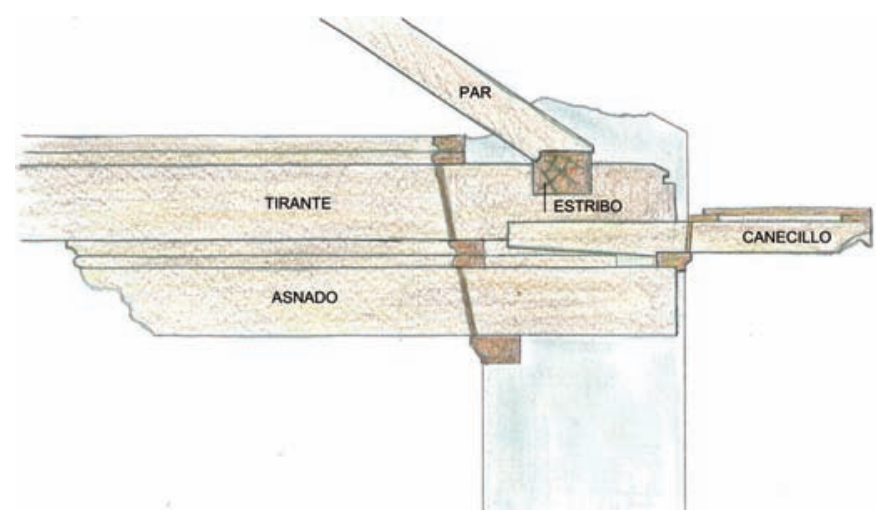

Fig. 9. Disposición de la armadura en su encuentro con el muro. Obsérvese la distancia entre canecillo y estribo 


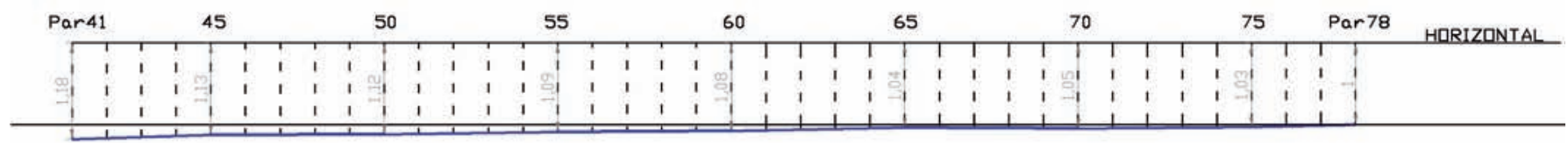

Fig. 10. En azul, la línea que representa la toma de niveles del estribo en el lado norte del par 41 al 78
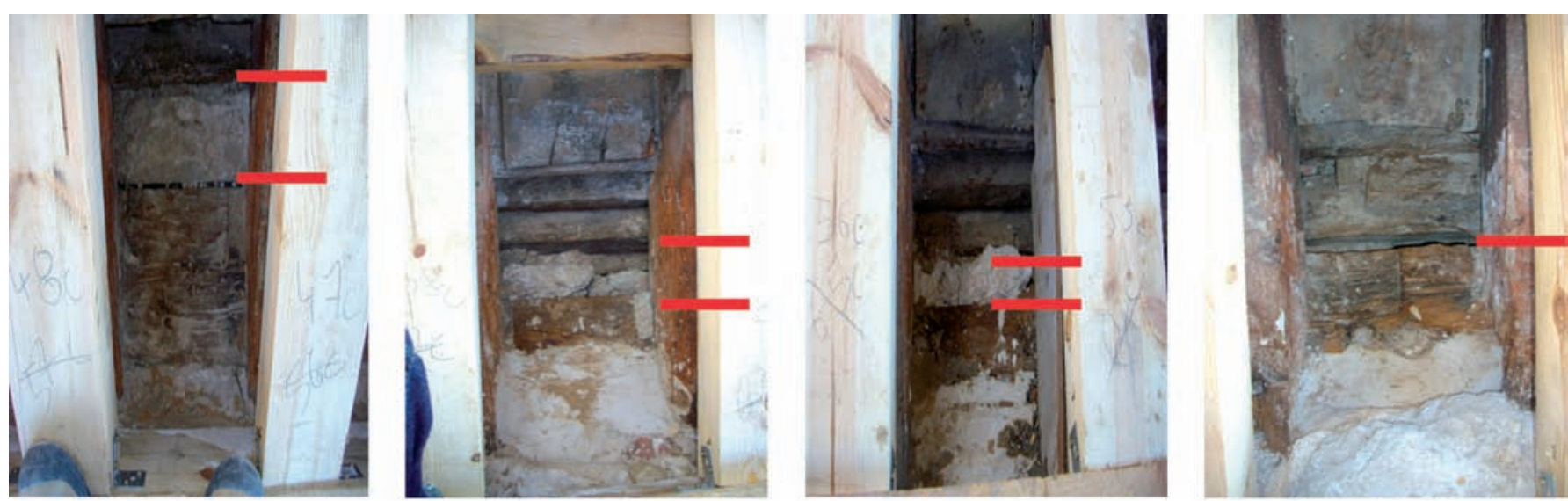

Fig. 11. Detalle del espacio macizado entre el estribo (línea inferior) y el arrocabe (línea superior), en el lado norte, entre los pares de izquierda a derecha: $47-48$ (12 cm), 55-56 $(7,5 \mathrm{~cm}), 60-61(5 \mathrm{~cm})$ y $65-64(2 \mathrm{~cm})$

lo cual implica que para evitar el vuelco de aquéllos, cabían dos opciones, el uso de fijaciones a modo de clavos, o un macizado que inmovilizase los canecillos. La cuestión estriba en el porqué de esa holgura de $12 \mathrm{~cm}$. La solución tradicional de un alero de una cubierta mudéjar se resuelve con la siguiente disposición en orden ascendente: sobre el muro se dispone la solera, a continuación el can interior o asnado, tirante con tocaduras intermedias, canecillos del alero, y por último, sobre el tirante (y sobre los canecillos), a media madera, apoya el estribo al que acometen los pares conectados al mismo a través de una apatenadura (fig. 9).

Se tomaron los niveles del estribo desde el par 41 al 78 en el lado sur, ante la sospecha de que la falta de horizontalidad de éste fuera la explicación de la variación de posición de los elementos. Efectivamente, se midió cada 5 pares a la cara superior del estribo, comprobando que éste se dispuso en su ubicación con una pendiente del $1,3 \%$ (fig. 10), lo que evidencia que el montaje no se realizó correctamente.

El espacio entre el arrocabe y el estribo va variando. Esto es debido a que ni la solera ni la disposición de asnados y tirantes están horizontales. Para conseguir que los pares formen un plano (el de cubierta), el carpintero se ve obligado a esconder el error dentro del muro; de esta manera varía la disposición del eje del estribo con el juego de 30 $\mathrm{cm}$ que le permite el espesor de los elementos (fig. 11).
En el encuentro de par y estribo se halla una pareja de clavos que aseguran la entrega por medio de apatenadura y barbilla del par al estribo (fig. 12). Además, la longitud de la apatenadura es el doble de la anchura del par, lo que permite ajustar en obra el replanteo del taller.

El proceso de montaje pudo ser desde los pies a la cabecera, ya que se encontraron dos marcas de acuerdo en dos armazones consecutivos; la más próxima al campanario está compuesta por cinco incisiones longitudinales, y la siguiente hacia el presbiterio de seis (fig. 13). Esta teoría no se ha podido comprobar con más armazones dado que la cata que se practicó sólo abarcaba estos dos, si bien, en la siguiente intervención, sería muy importante comprobar ese dato.

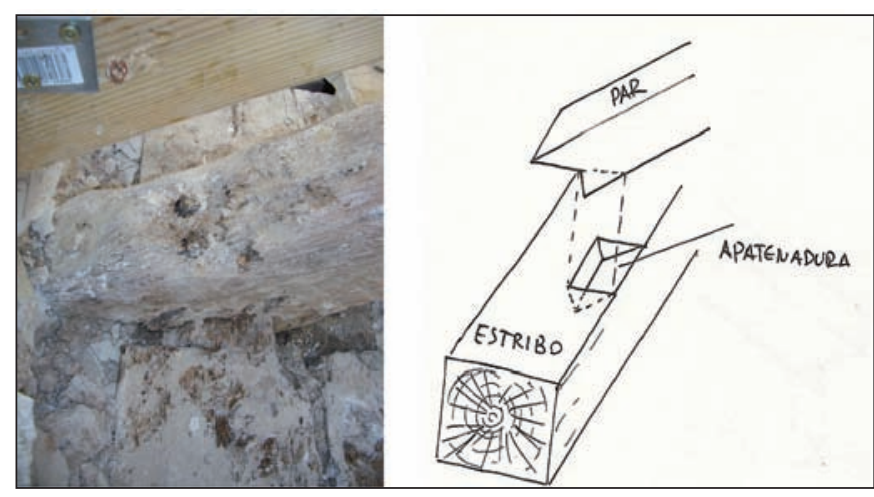

Fig. 12. Encuentro entre par y estribo a través de apatenadura asegurada con clavos 


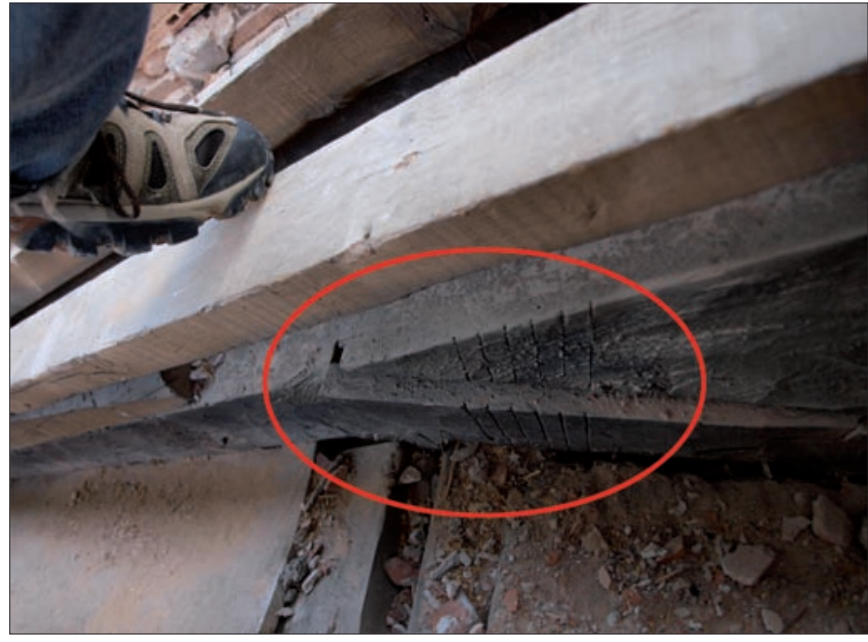

Fig. 13. Marcas de acuerdo en la unión nudillo-par

No se encontró ningún contracán ${ }^{8}$ en su posición original y sería necesario un ensayo dendrocronológico para saber si alguna de todas esas piezas multiformes pudo ser original (fig. 14). El hecho de que existiesen en los aleros tablas continuas en lugar de tablas menadas, tablas y saetinos, indica que todos los contracanes han sido retirados en algún momento, sustituyendo piezas, o recolocándolas. La mayor parte de ellos son reutilizados de una armadura anterior, tal y como demuestran los engargolados y las tallas de media madera practicados en ellos.

Una vez tomadas las cotas y estudiados todos los componentes del alero, es posible aventurar una hipótesis de montaje. Es importante tener en cuenta varios factores. En primer lugar, existen indicios que demuestran que la techumbre se montó después de haberla ensamblado previamente en taller por las marcas de acuerdo que aparecen y porque hay pintura por encima de éstas. También se sabe que se pintó en taller, por la disposición de las gotas de pintura y porque al desmontar alguna pieza se observaron trazos de color en zonas inaccesibles una vez montada. Se debe tener en cuenta la climatología de la ciudad y la labor delicada que supone montar esa techumbre. Es de suponer que el montaje se hizo en primavera, verano y parte del otoño y dado que la mayor parte del trabajo se hace en taller, es posible que durante ese periodo diera tiempo a montarla.

Considerando los $12 \mathrm{~cm}$ de separación vertical entre canecillo y estribo, se establecen dos posibilidades: esa holgura pudo permitir en su día montar el alero una vez

${ }^{8}$ Pieza de madera que conecta superiormente el canecillo del alero con el muro sobre éste. Su función es conformar la pendiente de la cubierta.

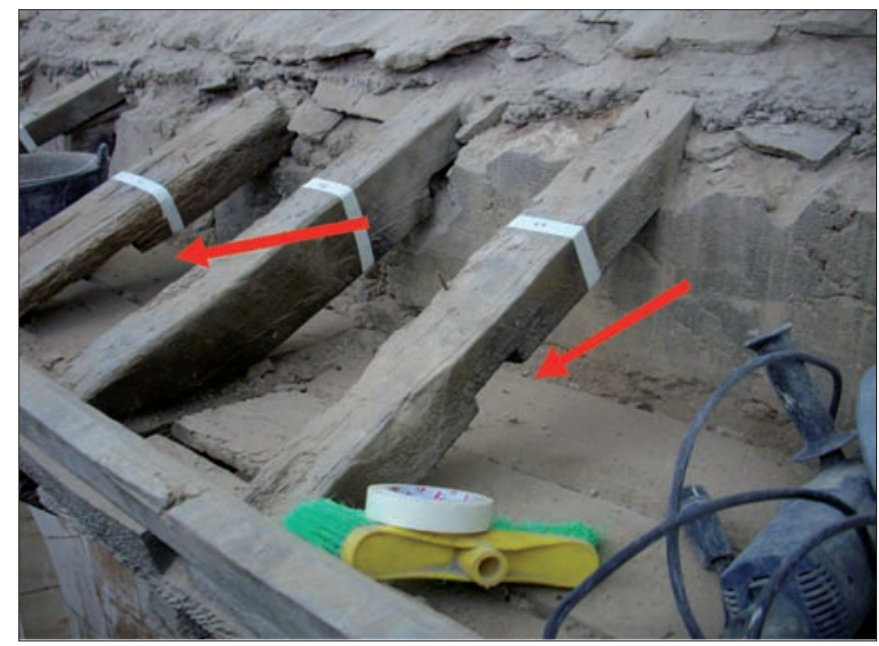

Fig. 14. Disposición de los contracanes. Se trata de piezas recuperadas de una armadura

concluido el montaje de la cubierta. El hecho de que los canecillos y los pares no tengan sus ejes alineados concuerda con esta posibilidad. O bien, pudo montarse el alero antes, para de esta manera, una vez puesta la techumbre, poder cubrirse acto seguido sin dilación. En este caso, el alero serviría como una cómoda plataforma desde la cual acometer el montaje de la cubierta.

Queda claro que la disposición de canecillos y pares no está relacionada y por lo tanto sus montajes pueden ser independientes. La luz entre canecillos es de $29 \mathrm{~cm}$ de media, es decir, un tercio de vara' ${ }^{9}$. Parece que en las dos hipótesis es necesario falcar los canecillos provisionalmente hasta que se inmovilicen con el tapial. Dado que se encontró más de un canecillo con clavos hacia la solera, se supone éste el falcado provisional que evitase el vuelco hasta el vertido del tapial que macizase el conjunto.

Estudiando con detenimiento la fábrica de tapia situada sobre el alero, se extraen varios datos. En primer lugar, se observaron los apoyos de los contracanes sobre la coronación inclinada de esta fábrica, siguiendo la pendiente de cubierta. Una vez colocados los pares y los canecillos, se macizó hasta conformar la anteriormente citada coronación inclinada. Esto se deduce de los restos de tapial encontrados en la apatenadura del estribo. Para ejecutar el macizado se hubo de encofrar por el lado exterior (queda patente en el acabado extremadamente liso, figura 14), mientras que en el otro, el alicer hizo de encofrado perdido. En varios puntos, éste está separado del macizado de tapial dimensiones considerables (hasta $13 \mathrm{~cm}$ ) origina-

\footnotetext{
${ }^{9} 1$ vara $=83.59 \mathrm{~cm} .1 / 3$ vara $=1$ pie. $1 / 4$ vara $=1$ palmo
} 
dos por algún movimiento estructural posterior. En consecuencia, queda descartado que ese relleno sea de la intervención de 1950 de Regiones Devastadas, ya que de ser así, los desplazamientos que delatan las separaciones, habrían generado alarma documentada. Lo que queda sin explicación es por qué el tramo sur desde el canecillo 42 hasta el 62 queda sin rellenar. Es posible que no estuviese previsto macizar pero que una vez concluidos los trabajos, ciertas piezas se moviesen y decidieran asegurar la estabilidad del conjunto empotrando alguno de los apoyos.

Dado el programa pictórico es de suponer que no se arriesgasen a que éste se arruinase por una tormenta o una nevada, así que es muy probable que cualquiera que fuera el orden constructivo, éste comprendiese la protección una vez montado cada tramo. Este proceso de ejecución de cubierta por tramos explicaría el porqué de los desniveles y de las grandes diferencias de ejecución de unos tramos a otros. Sería interesante contrastar las características de tramos enfrentados, ya que si son similares esta teoría quedaría ampliamente reforzada.

\section{POLICROMÍAS}

El ciclo iconográfico, valiosísimo, abarca una visión de la vida en el Medievo, una riquísima decoración figurativa, animal, geométrica y vegetal que cubre todos los elementos constructivos visibles desde el interior o exterior. Un $37 \%$ de toda la superficie decorada corresponde a pintura original sin repintes, un $23 \%$ a repintes bajo los cuales se conserva la pintura original, un $24 \%$ a repintes sobre la madera desnuda y un $15 \%$ a faltas o lagunas decorativas. Estas proporciones se calculan tomando el $100 \%$ de la superficie decorada, incluyendo los aleros ${ }^{10}$.

A lo largo de la historia, se ha tratado de buscar respuestas acerca de la autoría, datación e interpretación de tan vasta obra, y como consecuencia de la falta de fuentes documentales escritas, se ha utilizado la lectura de la propia obra para obtener esos datos. Se estudia el bestiario en relación con la literatura de la época, la indumentaria, el estilo, surgiendo así razonamientos cronotipológicos más o menos acertados. Hace siglos que las pinturas de los aleros se encontraban ocultas bajo una gruesa capa de suciedad, por lo que todos estos estudios se han basado en la observación y análisis de las pinturas del interior, no del exterior. La restauración llevada a cabo en los años 2008-2009 ${ }^{11}$ rescató los restos de policromías de los aleros, permitiendo la lectura completa de la techumbre interior-exterior. Además, si

\footnotetext{
${ }^{10}$ Cifras calculadas a partir de datos extraídos del informe de restauración de 1999 de la empresa Coresal, incluidos en Borrás, 1999: p. 62.

${ }^{11}$ Proyecto de restauración de Andrés Rubio, 2003.
}

bien las pinturas del interior del templo han sido intervenidas en tres ocasiones, que se tenga constancia ${ }^{12}$, durante la restauración del 2008-2009 se ha comprobado la ausencia de repintes o de indicios de intervención sobre las policromías de los aleros, lo que confiere un grado autenticidad único en el conjunto (fig. 15).

La restauración de los restos de policromías encontrados en los aleros ha consistido en rescatar las pinturas, limpiarlas, y protegerlas. En ningún caso se han añadido trazos, es decir, todos los restos son originales. Para abarcar el estudio de las policromías, se realizó una comparación formal y estilística de los elementos en el exterior siguiendo el método morelliano ${ }^{13}$, para lo cual se estudiaron detalles secundarios de la representación tales como las pezuñas de las bestias o la terminación de las orejas o las colas (fig. 16). Para poder llevar a cabo este estudio ha sido necesaria una sistematización en la toma de datos consistente en varias fotografías de cada elemento, selección de tomas, rectificación fotogramétrica de cada tabica, canecillo y tabla y montaje de todas las imágenes en su posición correspondiente con el fin de plasmar los aleros en el papel sin fugas ni deformaciones (fig. 17). Posteriormente estos archivos informáticos permiten agilizar el trabajo de comparación haciendo tantos montajes como sean necesarios (fig. 18).

$\mathrm{Al}$ comparar todas las tablas que representan motivos vegetales se observa una imagen que se repite varias veces, sin embargo no se aprecia ningún tipo de ritmo en su disposición, por lo que no podría catalogarse de decoración seriada, pero sí de repetitiva.

Existen varias tabicas que representan un mismo elemento (por ejemplo felinos, palomas o pelícanos), con las diferencias inherentes al pintado manual. Es importante destacar la increíble similitud entre ciertos dibujos que hacen pensar en la utilización de modelos o patrones. Sin embargo, en cuanto a la autoría, pueden distinguirse varias manos; existen representaciones cuyos trazos son más gruesos, de pulso más basto, y otras, cuyos trazos son más finos, de calidad pictórica más alta.

\footnotetext{
12 Pocos años antes de 1700, campaña de Regiones Devastadas 1939-1952 y restauración del IPHE en 1999.

${ }^{13}$ Entre 1874 y 1876 la revista Zeitschrift für bildende Kunst publica una serie de artículos (firmados por el ruso Iván Lermolieff y traducidas al alemán por Johannes Schwarze) en los que presenta el Método morelliano, que consiste en distinguir las pinturas originales de las copias. Para ello, según sostenía Giovanni Morelli (Verona, 1816 - Milán, 1891), no hay que basarse como se hace habitualmente, en las características más evidentes, y por eso mismo más fácilmente imitables, de los cuadros: los ojos alzados al cielo de los personajes de Perugino o la sonrisa de los de Leonardo. Por el contrario, se debe examinar los detalles menos trascendentes: los lóbulos de las orejas, las uñas, la forma de los dedos de manos y pies. Guinzburg, 1994: p. 139.
} 


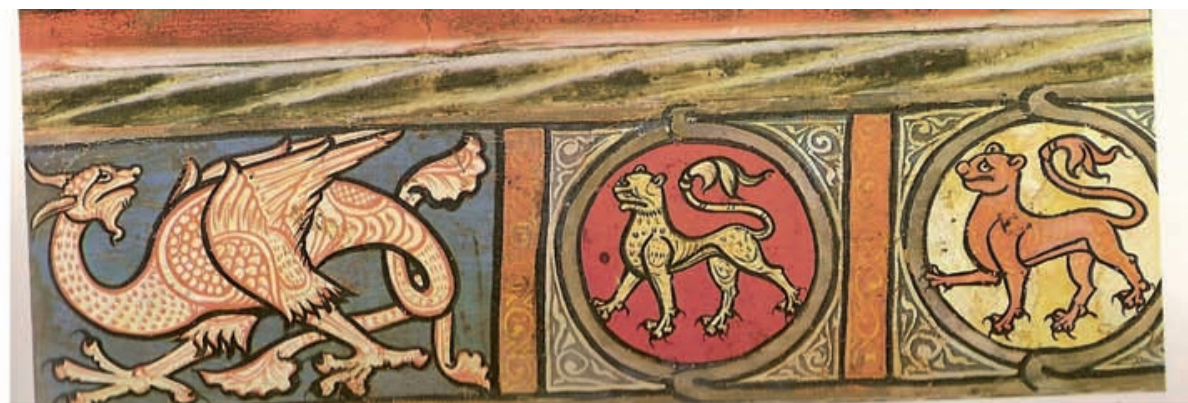

\section{Sección $6^{\text {a derecha }}$}

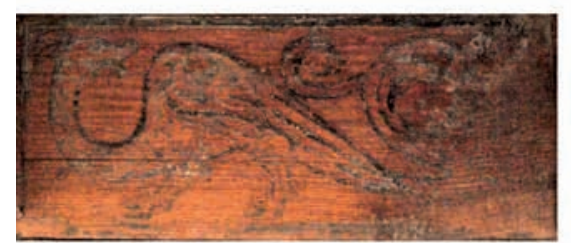

26-27 E

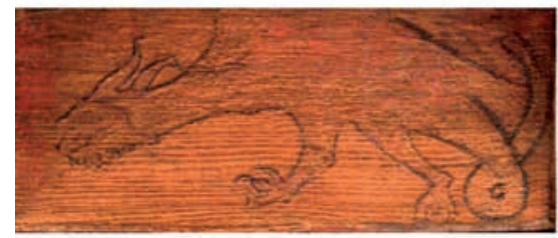

52-53 E

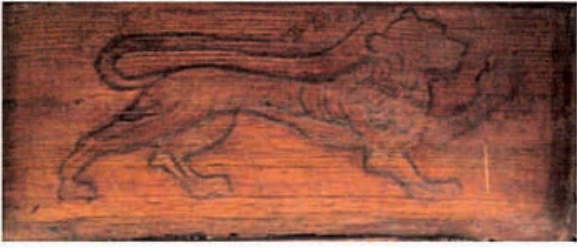

17-18 E

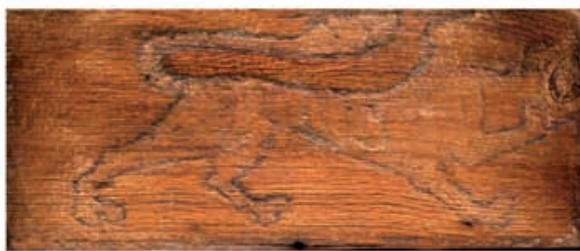

56-57 E

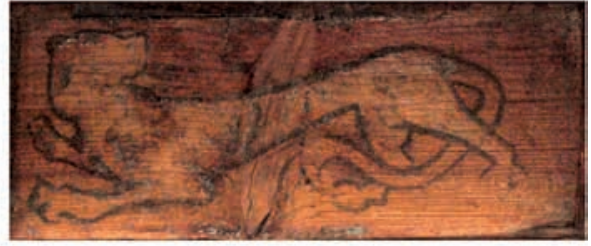

28-29 E

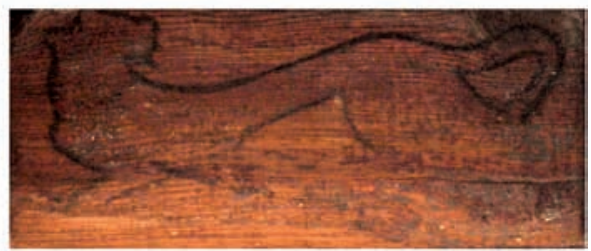

42-43 E

Fig. 15. Mismos animales representados en el interior (arriba) y en el exterior (línea intermedia y abajo). Destaca la naturalidad de la expresión en las del alero con respecto al forzado de expresiones de las del interior; dicha diferencia es fruto de las restauraciones. Aquí es donde radica la importancia de los restos del alero, que nunca (que se tenga constancia) han sido manipulados

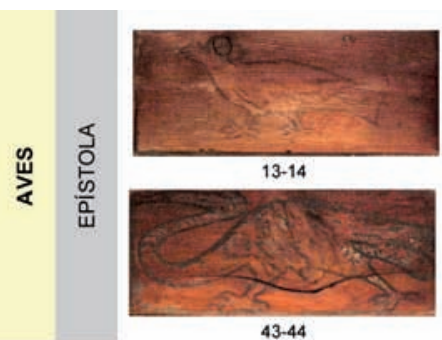

43-44

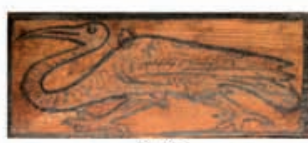

$31-32$

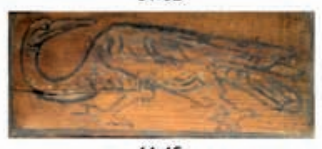

44-45

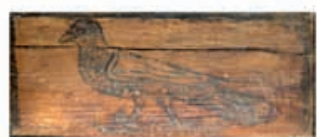

35-36

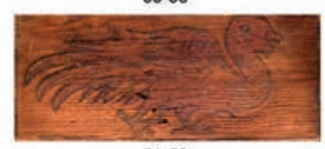

$51-52$

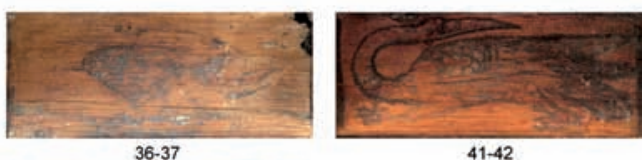

36-37

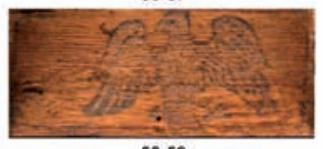

58-59

Fig. 16. Ejemplo de clasificación de policromías por tipología.

\section{1}
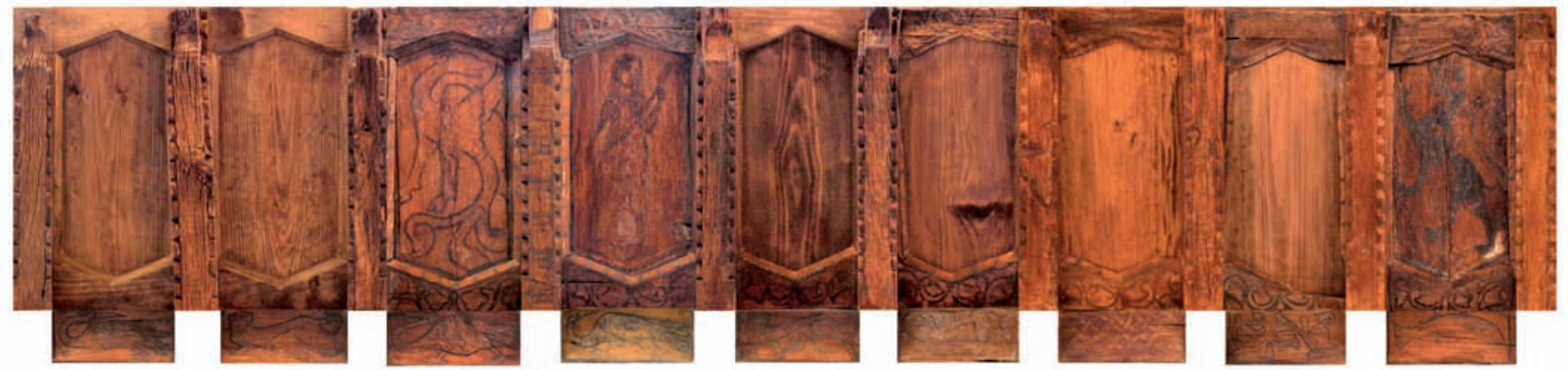

Fig. 17. Ficha del tramo del canecillo 41-50 en el lado sur (tabicas abatidas) 


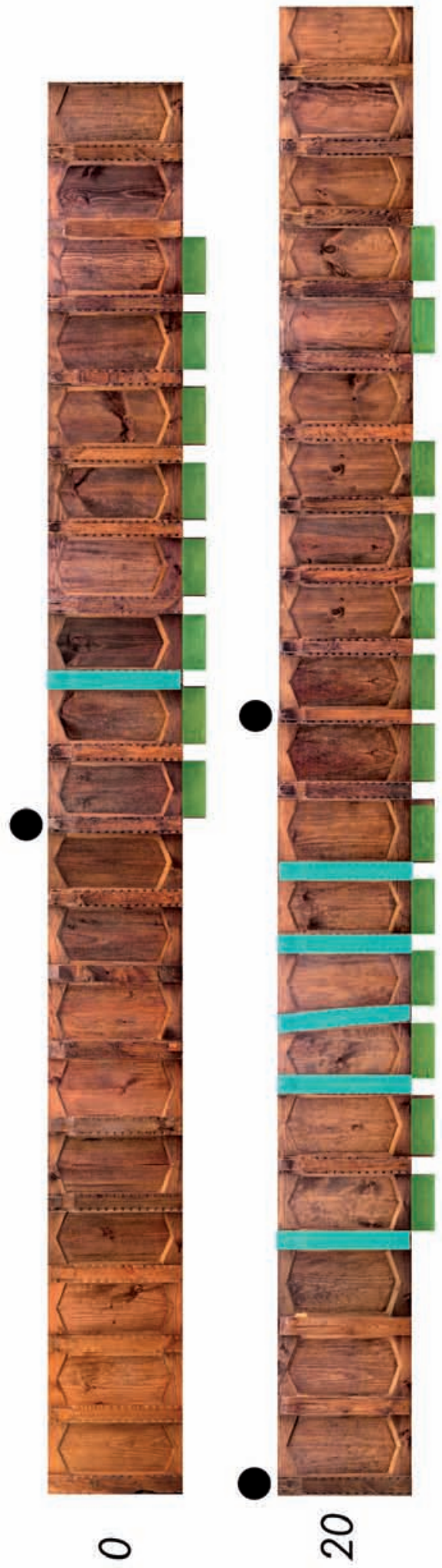

Ficha: Restos de Policromías. TRAMO 0 - 84 EPÍSTOLA
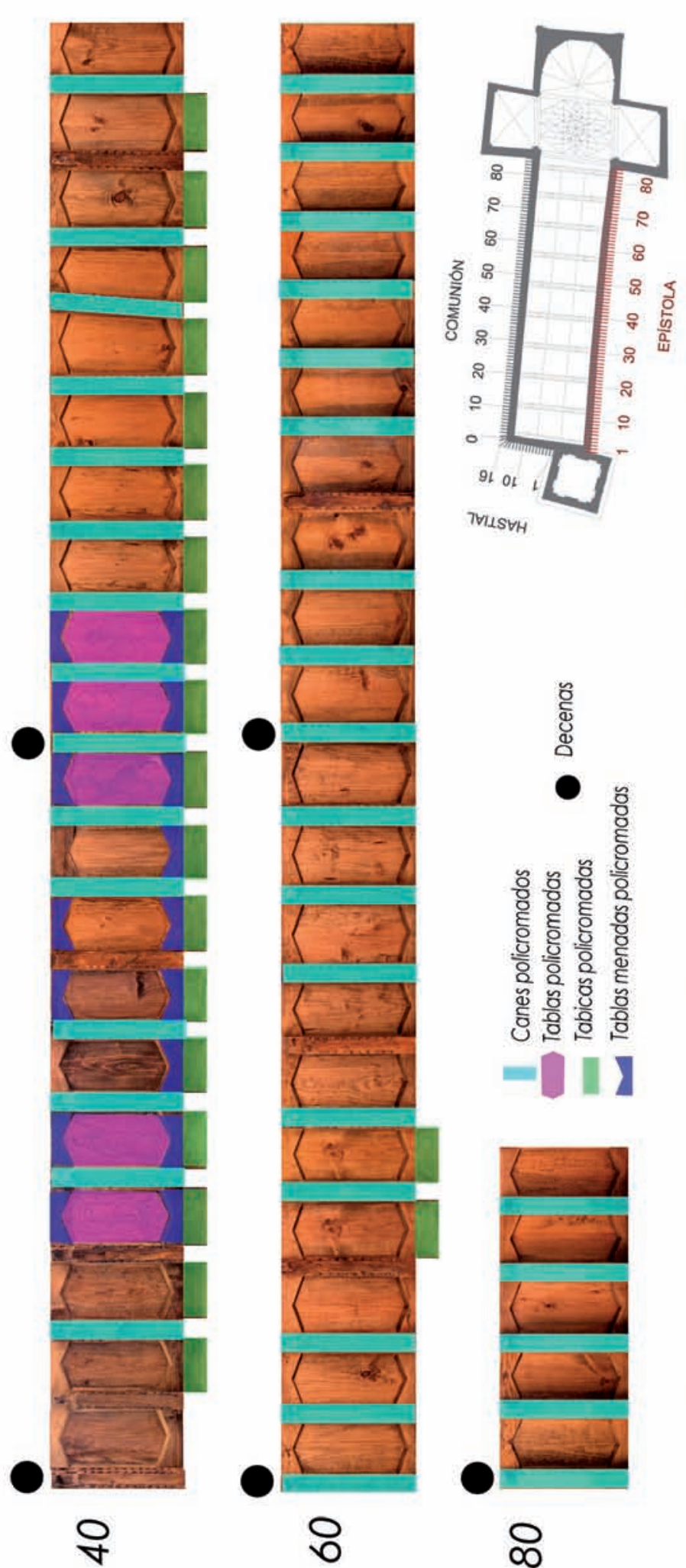

7HLSWH

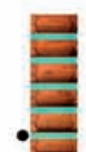




\section{HIPÓTESIS DE LOS PERIODOS CONSTRUCTIVOS}

Analizada la información estratigráfica y los archivos históricos, se establecieron las hipótesis de los periodos constructivos que han conformado la Iglesia, resultando cuatro fases constructivas, además de la última restauración del 2008:

\section{Fase 1}

Cronológicamente la fase 1 se enmarcaría entre el año 1177, fecha de la fundación de la ciudad ${ }^{14}$, y el año 1257 , fecha de construcción de la torre campanario. Además de los archivos que atestiguan la datación de la torre, se ha comprobado, gracias al estudio estratigráfico, que el cuerpo del campanario rompe al muro oeste en su parte inferior, lo que evidencia su posterioridad.

En la fase 1, la fábrica de la primitiva iglesia era de una altura menor que la actual (fig. 19), a tenor de las evidencias que siguen. Se comprobó que la estructura de madera embebida a 10,30 metros de altura en el muro hastial no es sino los restos de un antiguo alero; ello se sabe porque se identifican canecillos amputados y las incisiones que presentan corresponden al engargolado de las tabicas; en la posición previsible se aprecia claramente la solera y las improntas de los contracanes en el muro sobre el alero, y se comprueba cómo las medidas de los elementos coinciden plenamente con las del alero de la techumbre actual, 6,40 metros por encima. En fotografías tomadas en 1937, tras los bombardeos (fig. 20), se observa que existían huellas de la primitiva iglesia en el muro norte, en el espacio situado bajo el actual tejado de la nave lateral; se pueden apreciar restos de una posible ventana y mechinales, practicados en el muro, correspondientes al anterior tejado de la nave lateral. En la inspección del espacio comprendido entre la cubierta y el alfarje de las naves laterales se observó que en la fachada norte, la fábrica presentaba un escalón horizontal, el cual podría confirmar la teoría de que los muros eran de esa altura y posteriormente se sobreelevaron. El escalón no es constante, sino que desaparece próximo al cuerpo del cimborrio. Sin embargo, en el muro sur no se ha detectado escalón alguno. Asimismo, se documentó que la fábrica de la fase 1 por el exterior es de la misma composición y técnica de ejecución que el tapial inmediatamente superior.

Se podría establecer que la primitiva iglesia constaba de una única nave cuya altura sería la definida por el alero del muro oeste $(11 \mathrm{~m})$ y una anchura igual a la actual $(8 \mathrm{~m})$. La inexistencia de improntas de contrafuertes o arranques de arcos confirma que la nave se cubriría con

${ }^{14}$ Ibañez, 2002: p. 16.
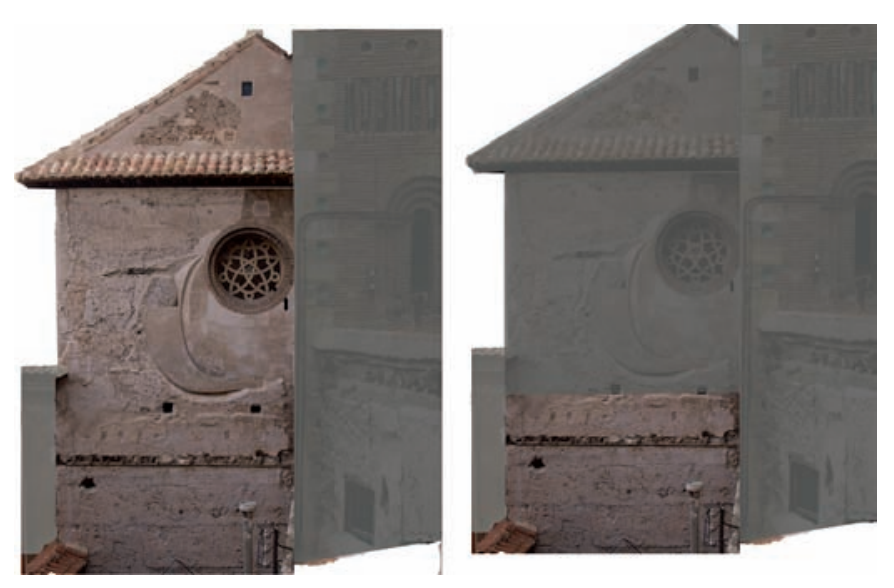

Fig. 19. A la izquierda, el muro hastial actual, a la derecha zona del muro perteneciente a la fase 1 , definida por el escalón y los restos del alero

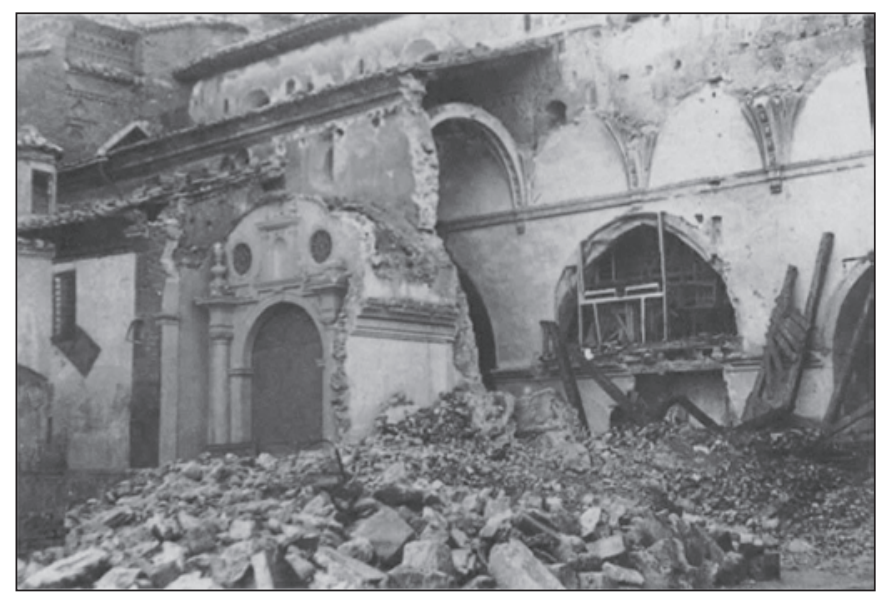

Fig. 20. Fotografía tomada durante la Guerra Civil. 1937. R. Atrian

una techumbre de madera, apoyada sobre muros de tapia de yeso.

\section{Fase 2}

Durante la fase 2 se amplió el templo, sobreelevando los muros de la nave central y ejecutando las naves laterales; esta ampliación se puede datar entre dos fechas documentadas, la edificación del campanario en 1257-1258 y el enlucido del ábside en $1335^{15}$.

Tanto en la fachada sur como en la norte, el nuevo muro se ejecutó con 9 ventanas alargadas con arco de medio punto, que son las que ahora iluminan la techumbre. Los muros se componen de machones (en jambas) y arcos de ladrillo a rosca conformando los huecos, y de fábrica de tapia de yeso entre ellos (fig. 21). En la

${ }^{15}$ Cuaderno de cuentas conservado en el Archivo Catedralicio de Teruel, titulado Recepta de la obra de Sancta María, que data del año 1335. 

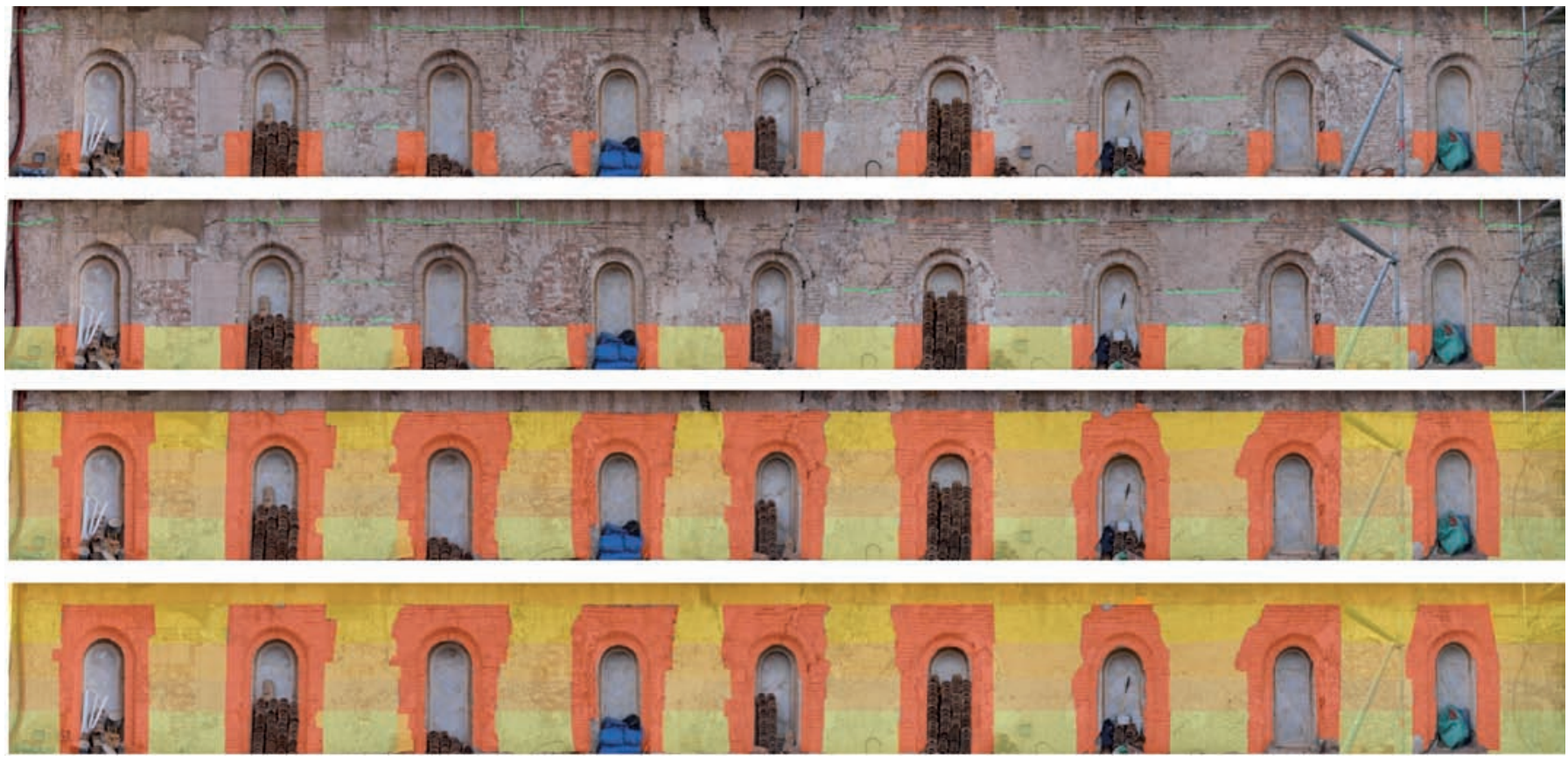

Fig. 21. De arriba a abajo, proceso de ejecución de los muros longitudinales en la fase 2
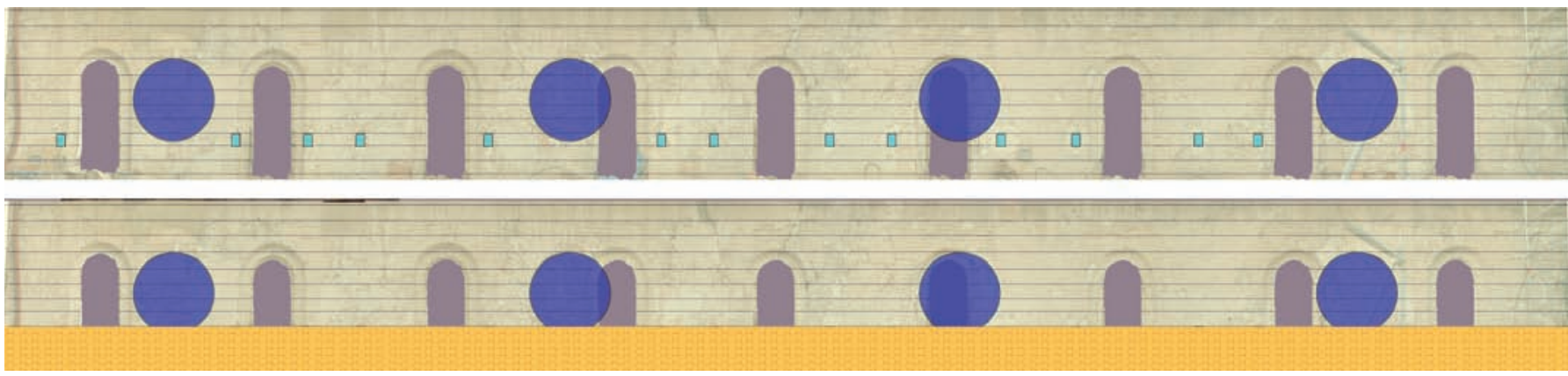

Fig. 22. En la fase 3, se ciegan las ventanas medievales (gris) y se abren cuatro óculos (azul). Además, se cajea el muro (arriba) para recibir los pares de la nueva cubierta (abajo)

actualidad las jambas se componen de dos arquivoltas; al retirar el mortero que recubría a éstas quedó al descubierto el ladrillo, comprobando con asombro que la arquivolta interior presentaba los ladrillos degollados de forma alterna, lo cual evidencia la existencia de, al menos, una arquivolta más hacia el interior, eliminada en alguna intervención posterior. Así pues, en un origen las ventanas de la nave central tendrían tres arquivoltas como las del campanario y el presbiterio.

La ubicación actual de la techumbre se enmarca dentro de esta fase como atestiguan los elementos hallados embebidos en los muros, tales como soleras, asnados y durmientes.

En la sobreelevación del muro hastial se practicó un gran óculo, del cual no se tenía constancia documentada hasta la fecha (fig. 24).

\section{Fase 3}

Los muros de la iglesia permanecieron sin grandes cambios hasta aproximadamente finales del siglo XVII, cuando se realizaron intervenciones de gran importancia que alteraron el aspecto interior $y$, en menor medida, la imagen exterior de la iglesia. Las obras consistieron en el enmascaramiento interior del templo y la construcción de bóvedas de arista en su nave central y de crucería en sus laterales, documentadas en fotografías históricas (fig. 23) y en los croquis realizados por Juan Cabré Aguiló ${ }^{16}$. Los indicios encontrados tras la eliminación del revestimiento en el año 2008, afirmaron que se habían cegado las ventanas originales de los muros longitudinales de la nave central y que se habían practicado cuatro óculos de aproximadamente dos metros

\footnotetext{
${ }^{16}$ Cabré, 1909-1910: manuscrito.
} 


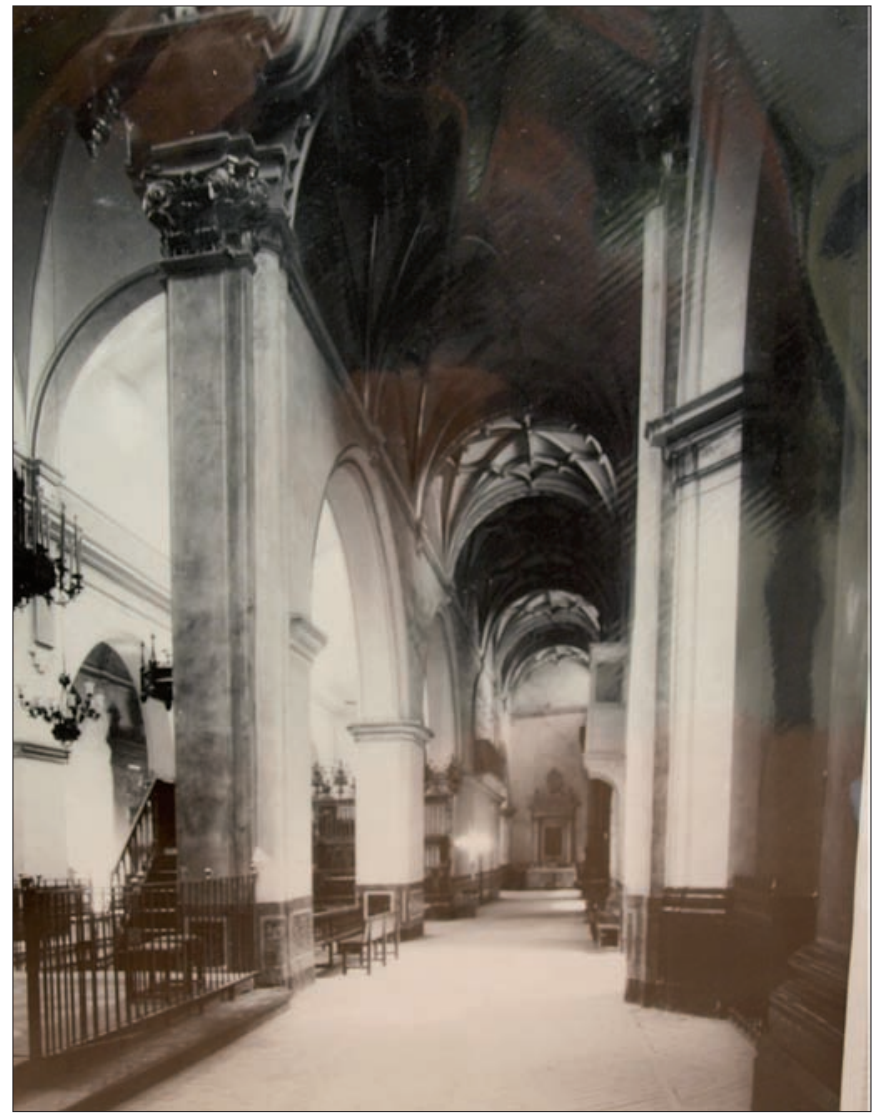

Fig. 23. Fotografía del interior del templo en 1932. Archivo Mas

de diámetro en cada fachada longitudinal, coincidiendo con los lunetos de la bóveda de arista. En las naves laterales, la cubierta interfería con las bóvedas de crucería, por lo que se desmontó y se ejecutó una nueva con más inclinación que la anterior, tal y como demuestra la línea de mechinales que albergaban los nuevos pares (fig. 22) Afortunadamente, en la nave central no fue necesario alterar la armadura, ya que las nuevas bóvedas no alcanzaban la techumbre medieval.

En el muro hastial las transformaciones sufridas en esta fase consistieron en la modificación del óculo medieval para darle una forma ovalada más acorde con el nuevo estilo del templo (fig. 24).

\section{Fase 4}

La iglesia permaneció en estilo barroco hasta la Guerra Civil, cuando las bombas arrojadas sobre la ciudad de Teruel causaron graves daños en la parte de la techumbre más próxima al hastial y en la zona norte de la catedral.

Durante los años de posguerra, entre 1940-1953, la campaña de Regiones Devastadas llevó a cabo una restauración en estilo. Las obras consistieron principalmente en

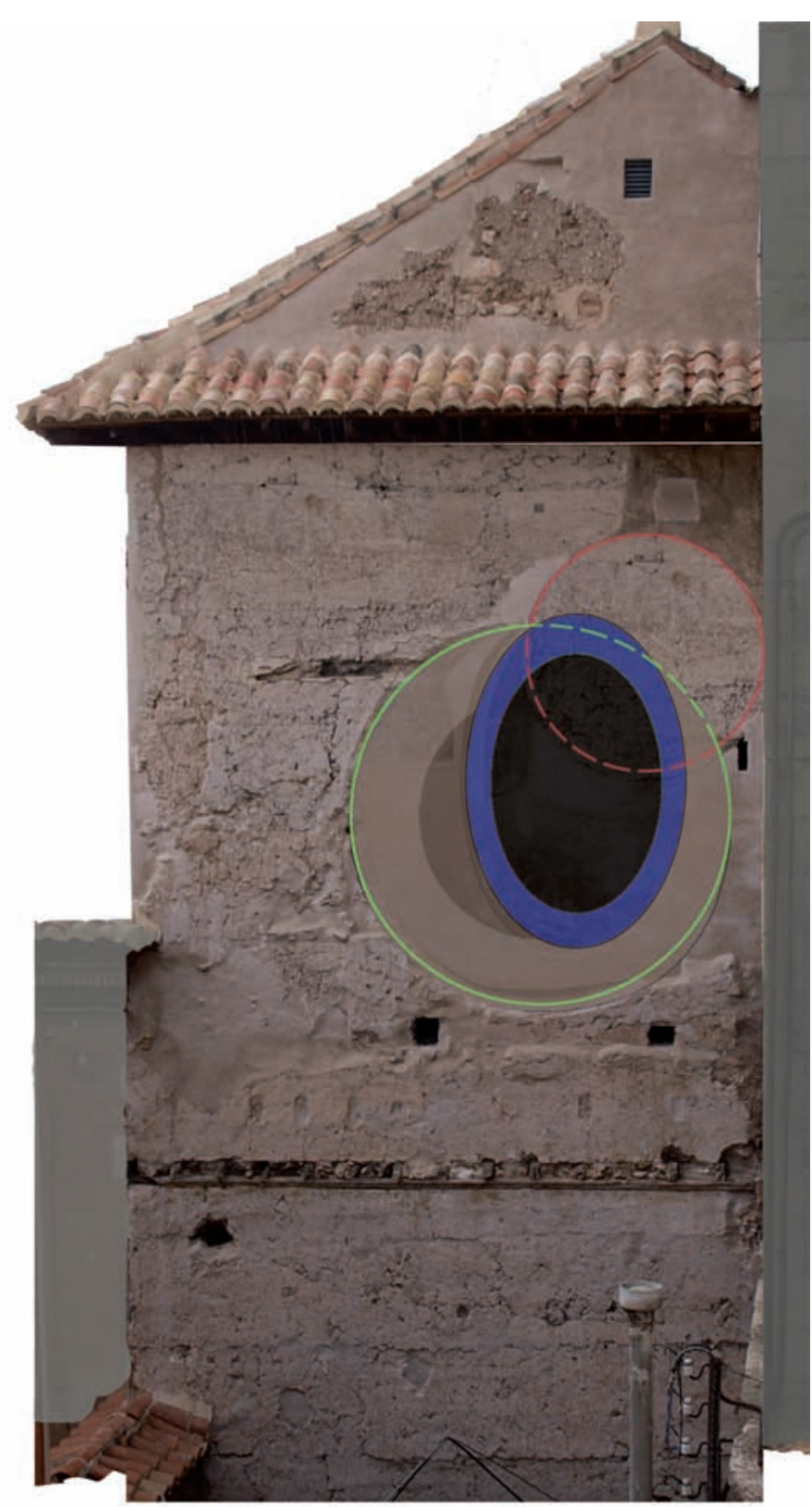

Fig. 24. Recreación de la ventana del muro hastial en la fase 3 (azul). En segundo plano se aprecia el óculo circular de la fase 2 (verde) y el actual óculo (rojo)

la reparación de los daños, la ejecución de una nueva cubierta y en la eliminación de los revestimientos barrocos. Se cegaron los óculos, se recuperaron las ventanas de época románica (figs. 25 y 26) y se derribó la bóveda de arista, poniendo en valor la techumbre de la nave central. A este respecto se nos ha informado ${ }^{17}$ de que Manuel Chamoso ${ }^{18}$ contaba que "las bóvedas que ocultaban la armadura las

\footnotetext{
${ }^{17}$ Agradecemos a Antonio Almagro Gorbea los datos recogidos en el texto.

${ }^{18}$ Manuel Chamoso Lamas (1909-1985), historiador del arte y arqueólogo, que participó en la restauración llevada a cabo por Regiones Devastadas.
} 


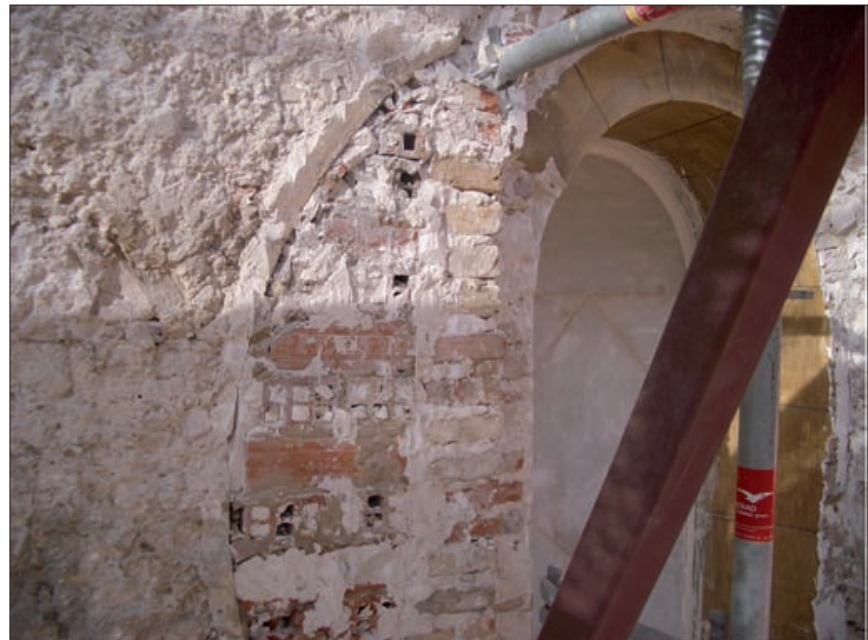

Fig. 25. Óculo, situado en el muro sur, cegado con fábrica de ladrillo moderno demolió él con una brigada de obreros a su mando que iba detrás del avance del ejército para recuperar y tomar medidas urgentes en los monumentos. Sólo habia un boquete abierto en un tramo por la caída de una bomba que también dañó un sector del techo de madera que quedó destruido. Pensó que era el momento y la excusa idóneos para dejar visible la techumbre, que era bien conocida pues se podia ver por encima de las bóvedas. Alegando peligro de ruina, demolió las bóvedas tabicadas de finales del XVII de la nave central》.

En el muro hastial, al contrario que en los muros longitudinales, no se recuperó el óculo medieval, quizás por su desconocimiento; se cegó el óculo ovalado de finales del siglo XVII y se abrió uno nuevo con forma circular en una posición más elevada y más centrada con respecto a la nave. Este óculo es el que existe en la actualidad.
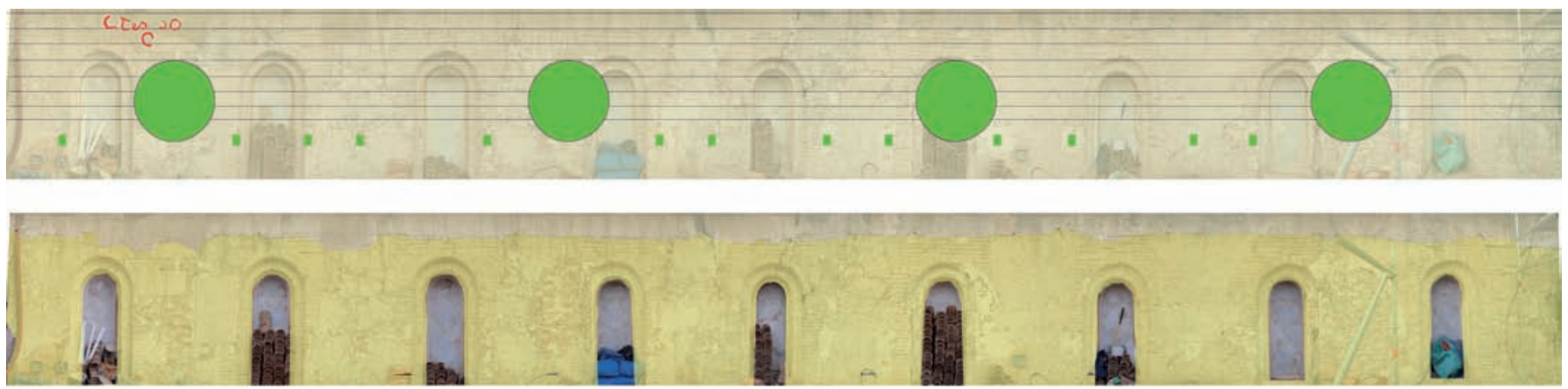

Fig. 26. En la fase 4 se ciegan las ventanas circulares y los cajeados de los pares, y se abren las ventanas medievales. Se reintegran las lagunas faltantes del esgrafiado.

Probablemente en esta fase se elimina la arquivolta interior

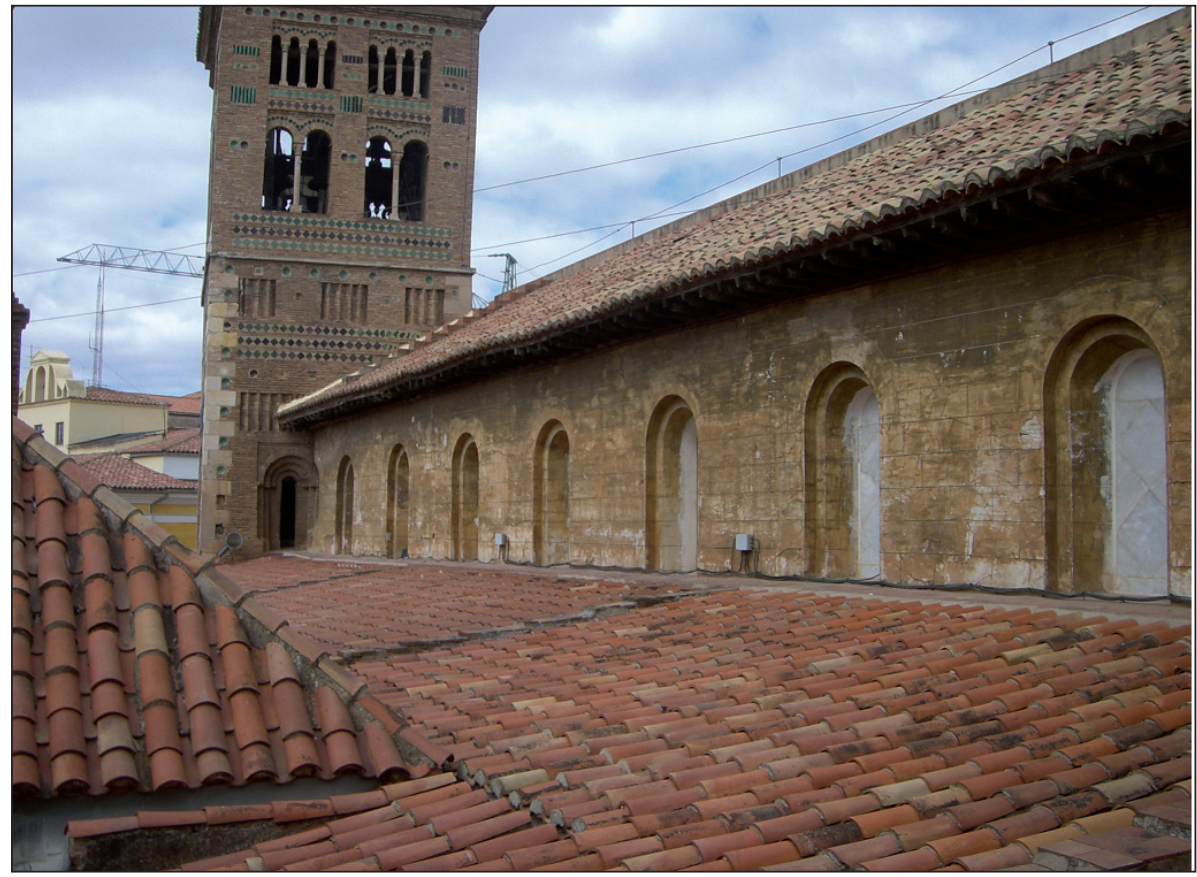

Fig. 27. Muro sur en 2007 


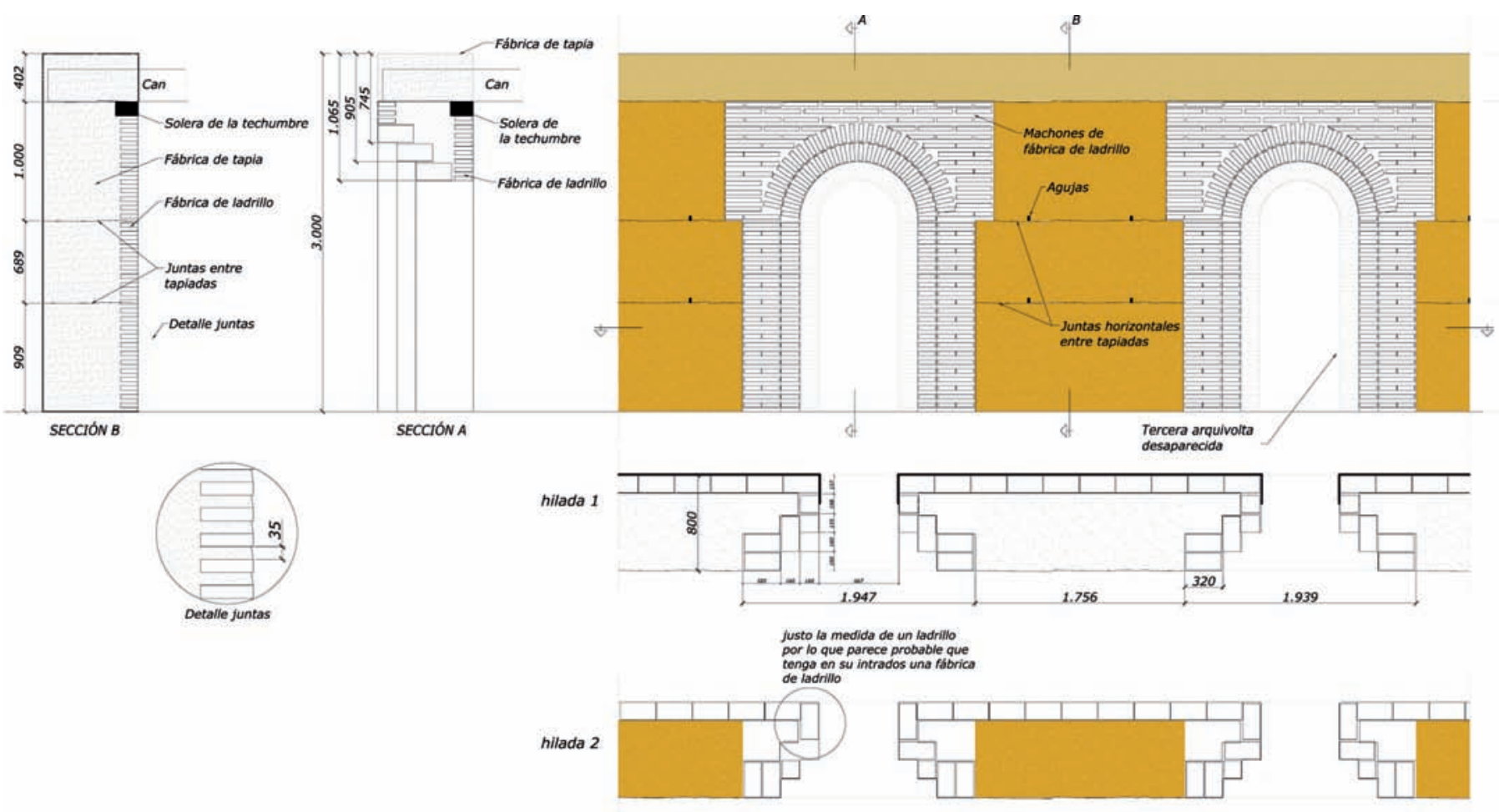

Fig. 28. Estudio constructivo de los muros longitudinales

\section{Fase 5}

Durante la segunda mitad del siglo XX se realizaron varias intervenciones en la techumbre, pero ninguna que afectara a los muros en estudio. En el año 2008 se efectuaron los trabajos de eliminación de revestimientos en los muros longitudinales de la nave central, el refuerzo estructural en la esquina oeste, el sellado de fisuras y el posterior revestimiento esgrafiado con mezcla de yesos tradicionales rojo y blanco de Albarracín. Cabe destacar que el revestimiento más moderno (1950) se encontraba en peor estado que el revestimiento anterior al siglo XVII, situado en su parte superior y protegido por el alero (fig. 27). En el muro hastial, se llevó a cabo una limpieza exhaustiva del paramento y un sellado preventivo de algunos huecos; se buscó una congelación del elemento en el tiempo. Es de destacar el valor histórico de este muro, ya que su situación de difícil visualización y acceso han provocado su paso desapercibido a lo largo de la historia, lo que le ha librado de ser alterado. Se puede afirmar que es una de las mejores ventanas arqueológicas que posee el templo y el conjunto de la ciudad, y que su lectura es una lección de historia de la arquitectura.

\section{CONCLUSIONES}

Las aportaciones del estudio se centran en las fases y procesos constructivos de los muros superiores de la nave central y en su encuentro con la techumbre mudéjar.
Tanto el muro del hastial como los que conforman la nave central de la catedral de Teruel, están realizados mediante la técnica del tapial, tal y como evidencian las agujas originales y las improntas de los cajones utilizados para su construcción. La peculiaridad en este caso estriba en que se combina con una fábrica de ladrillo en su intradós colocado a soga, haciendo las veces de encofrado perdido, solidarizándose con los machones de ladrillo que refuerzan y conforman las ventanas (fig. 28). Las juntas entre ladrillos, tanto de los machones como del intradós, se resuelven rematándolas hacia el interior por su parte superior, detalle común en fábricas mudéjares. Gracias a una difracción de rayos X efectuada en 2008, se sabe que la composición de la tapia es principalmente de yeso, y en menor medida, áridos finos y carbón vegetal; también contiene ripios y mampuestos de piedra en su interior.

Se verificó que las ventanas de medio punto de la nave central no datan del siglo XX, sino que son coetáneas a los muros mudéjares que las albergan, construidos entre 1257 y 1335. Se descubrió que las ventanas poseían, al menos, una arquivolta más hacia el interior. En el muro hastial, se hallaron y documentaron los restos de un gran óculo de época medieval, con unas dimensiones aproximadas de 3,13 m de diámetro, datado entre la segunda mitad del siglo XIII o principios del XIV. Superpuesto a éste, se descubrió un óculo con forma oval, datado a finales del 

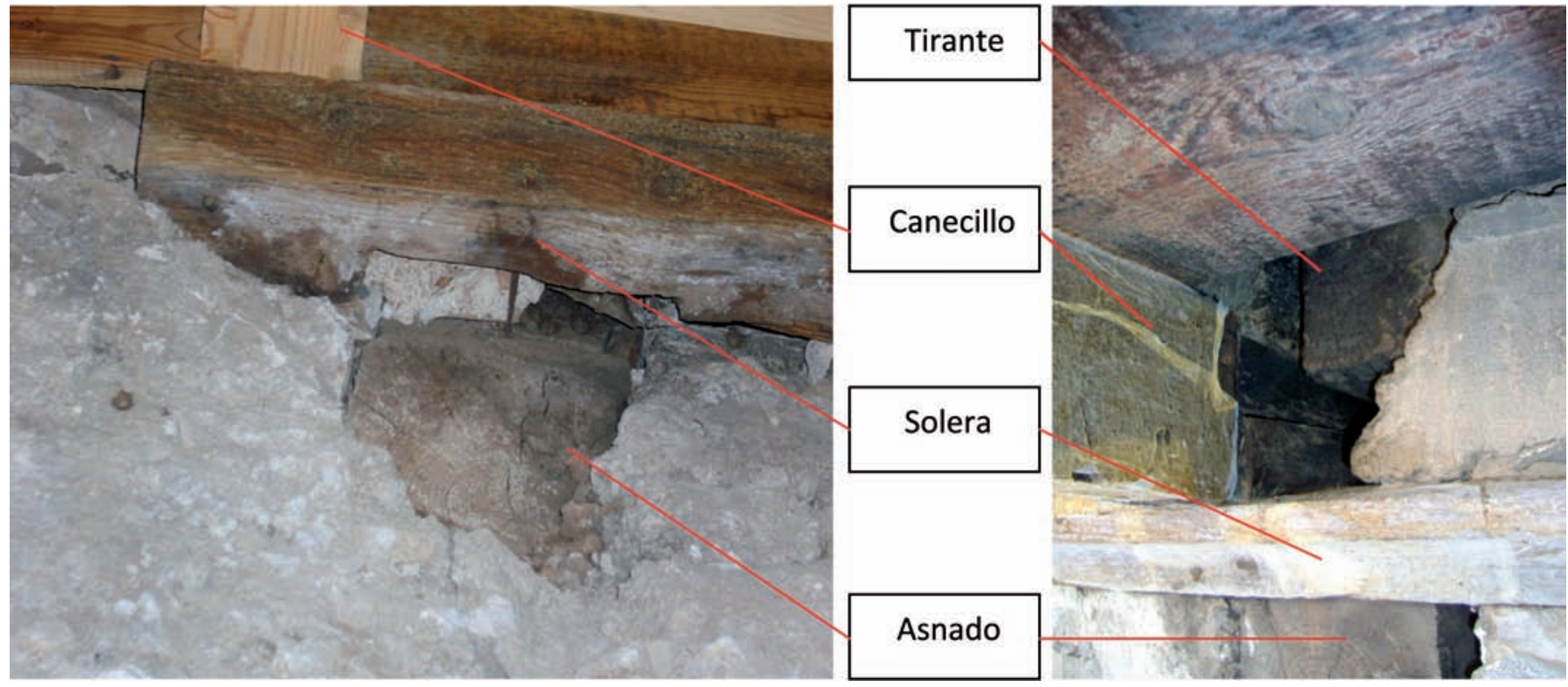

Fig. 29. Detalle de cajeo en la solera del alero al interseccionar con el asnado (izquierda) y de cómo los canecillos deben sortear a los tirantes (derecha)

siglo XVII y principios del siglo XVIII, que se encontraba cegado. De la misma época son los cuatro óculos cegados que se hallaron en las fachadas longitudinales y que se relacionan con las bóvedas de arista que cubrieron la nave central hasta mediados del siglo XX, momento en el que se procede al tapiado de éstos.

En el muro hastial se comprobó, mediante la eliminación estratégica de una parte del revestimiento, que el primer cuerpo del muro (hasta los restos de alero embebidos en el muro) es anterior al campanario ya que la fábrica del campanario rompe a la de la nave. Se construyó por tanto, entre los años 1171 y 1257 . La parte superior es posterior ya que la fábrica de la nave se adosa a la del campanario, por lo tanto se construyó entre 1257 y 1335.

Se han encontrado restos que demuestran que el primer revestimiento de los muros longitudinales de la nave central fue un enlucido liso de yeso, que cubría tanto la fábrica de ladrillo como la tapia de yeso. Posteriormente, en algún momento antes de 1700 , se revistieron los muros longitudinales en su cara exterior con un esgrafiado de fingido de sillares. Esto se deduce de las fotografías tomadas antes de 1940 en las que se aprecia el esgrafiado alrededor de las ventanas románicas cegadas y en desuso desde finales del siglo XVII hasta mediados del siglo XX.

Se ha verificado que el montaje de la techumbre es coetánea al cuerpo superior de los muros, tras comprobar que los asnados, durmientes y soleras que la soportan quedan embebidos en la fábrica de tapia. Los niveles de la techumbre no son horizontales, lo cual obligó al carpintero a variar, durante la construcción, la ubicación de los elementos insertados en el muro, de manera que puedan ocultarse los errores de montaje, que son abundantes (fig. 29). Esto pudo deberse, entre otros factores, a la reutilización de piezas de una armadura anterior. De haberse calculado bien, las tocaduras deberían haber medido unos cuatro centímetros más, así los canecillos se podrían haber dispuesto compartiendo eje con los pares y el macizado se podría haber evitado. En cuanto al orden de montaje, queda demostrado que la solera interior, los asnados, los tirantes, la solera del alero y los estribos, ya estaban montados cuando se colocaron los canecillos. Además, el intereje de los canecillos varía entre 28 y $31 \mathrm{~cm}$, para poder adaptarse a los elementos preexistentes.

En lo que a la formación de las pendientes se refiere, la disposición que se asumía hasta la restauración del 20082009 era que los contrapares habían sido pasantes, apoyando un extremo en los pares y en el otro en la cabeza de los canecillos, para conformar la pendiente del tablero sobre el que se disponían las tejas. Se descubrió que la distribución no era tal, entre otros factores, porque los ejes de par y canecillo no están alineados. Además, el macizado de tapial sobre el alero no permite que así sea ya que interseccionaría con el contrapar (fig. 30).

Se desconoce la cubierta que tenía la iglesia antes de la sobreelevación llevada a cabo entre 1257 y 1335, aunque todo parece indicar que esta primitiva cubierta consistía en una estructura de madera similar a la actual, de manera que no transmitiese empujes horizontales a los esbeltos 

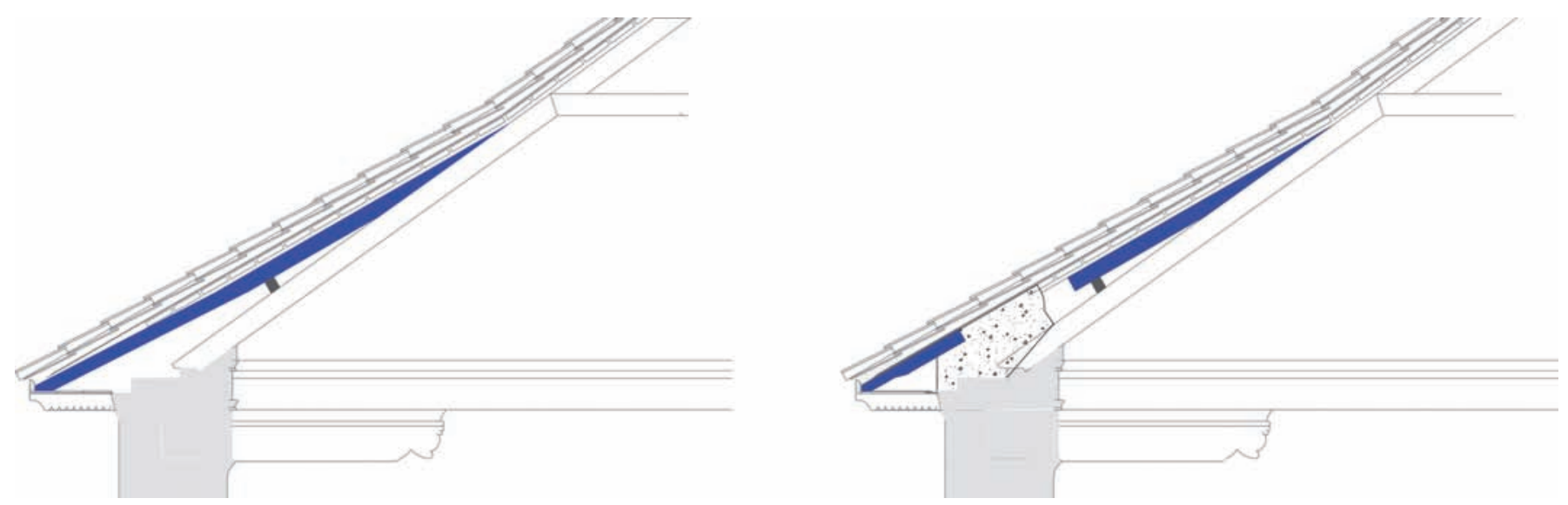

Fig. 30. A la izquierda, cómo se suponía la disposición del contrapar. A la derecha, la realidad encontrada en 2008
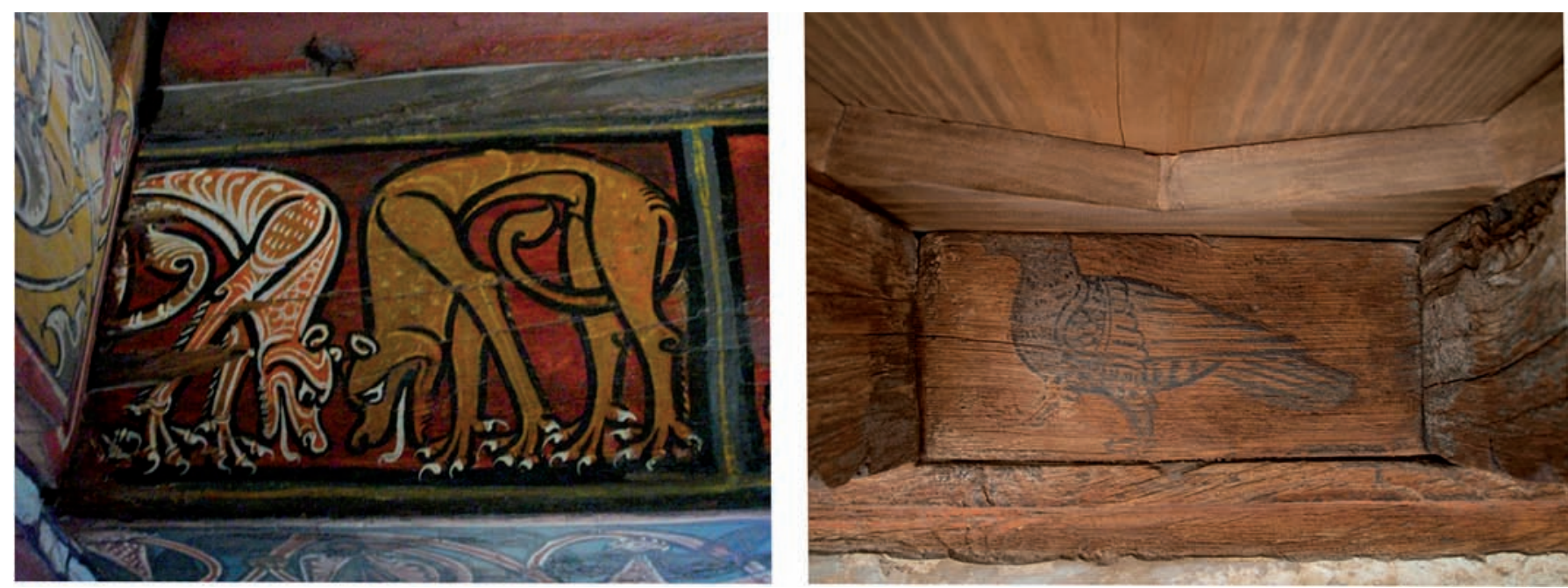

Fig. 31. Pinturas seccionadas

muros. Considerando las características del edificio, que la luz a cubrir es de aproximadamente 8 metros, que la madera es abundante en la zona y que no existen vestigios de contrafuertes u otros refuerzos en los muros, es de suponer que la cubierta se resolvía con una estructura de similares características a la actual. Era práctica habitual, en la medida de lo posible, reutilizar los materiales a la hora de acometer una reforma, por lo que parece lógico asumir que ciertas piezas de esa cubierta primitiva pudieron ser reutilizadas. Esta posibilidad se refuerza con varios indicios: durante la restauración de las policromías en el año 1999, los técnicos del IPHE argumentan en su informe final que tres de los asnados no pertenecen en tipología a esa techumbre dado que los engargolados y las medidas no coinciden con los del resto de las piezas ${ }^{19}$. El

\footnotetext{
${ }^{19}$ Borrás, 1999: p. 90.
}

can que se encuentra en el Museo Arqueológico Nacional $^{20}$, en el que se basa Torres Balbás para datar la techumbre, pertenece a la misma tipología que estos tres. En cuanto a las pinturas, varios autores, como el Profesor Joaquín Yarza ${ }^{21}$ o profesor Serafín Moralejo ${ }^{22}$, destacan que hay algunas ciertamente arcaicistas. Éstas pudieron pertenecer al artesonado anterior, o bien, servir para inspirarse a los pintores. Existen varios casos de pinturas sobre soportes que están cortados, como si la madera le quedara pequeña al pintor. Ocurre tanto en el interior como en el exterior (fig. 31) y pudo deberse a una reutilización de las piezas o en otros casos a un mal montaje o replanteo, que obliga a adaptar las maderas una vez pintadas e izadas. En el ámbito

\footnotetext{
${ }^{20}$ Museo Arqueológico Nacional. C/ Serrano, 13. 28001 Madrid

${ }^{21}$ Yarza, 1981: pp. 41-70

${ }^{22}$ Moralejo, 1986: p. 104, vol. 1
} 


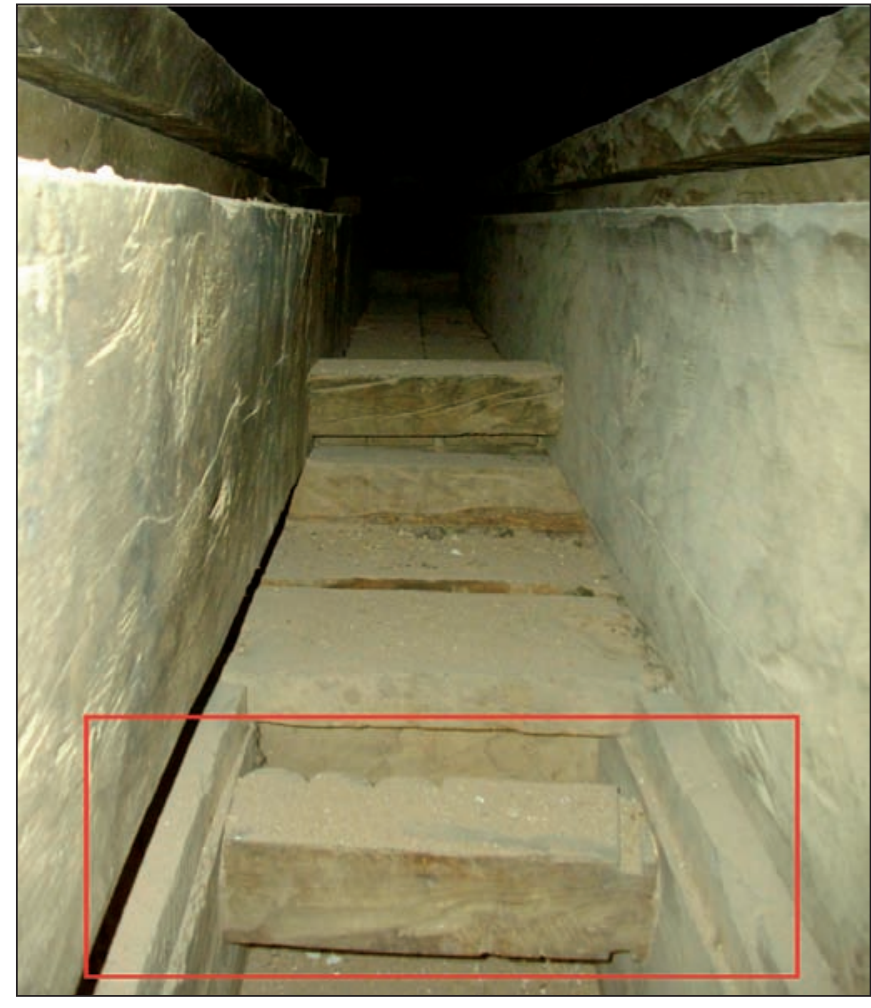

Fig. 32 Canecillo reutilizado en un tirante de la techumbre

constructivo, cabe señalar que algunas de las cabezas de los tirantes que quedaron al descubierto durante la restauración del 2008-2009 presentaban incisiones (probablemente de izado) diferentes entre ellas. La explicación sería que, o bien trabajaron varios equipos de carpinteros con procedimientos distintos, o bien se trata de elementos de una techumbre anterior. Se hallaron dos piezas reutilizadas: una moldura tallada empleada en la cara interna del alicer y un canecillo haciendo función de codal en el interior de un tirante (fig. 32). Así mismo, durante la restauración 2008-2009 se encontraron los restos de un antiguo alero en el muro hastial (fig. 33). Estos restos guardan exacta disposición constructiva al actual alero de la techumbre y sus elementos, canecillos, solera e interejes, tienen las mismas dimensiones. Además, el alero continuaba por ambos lados como se aprecia en los toscos cortes en ángulo recto de la solera, realizados en algún momento posterior a su colocación.

Uno de los datos más concluyentes, es el ensayo de carbono 14 practicado durante la restauración 2008$2009^{23}$. Se extrajeron tres muestras, una perteneciente a un par de la armadura (72C), otra a un canecillo contiguo a

${ }^{23}$ Ensayo realizado por AIDIMA el 11 de marzo del 2009, encargado por la empresa constructora EDYCON.

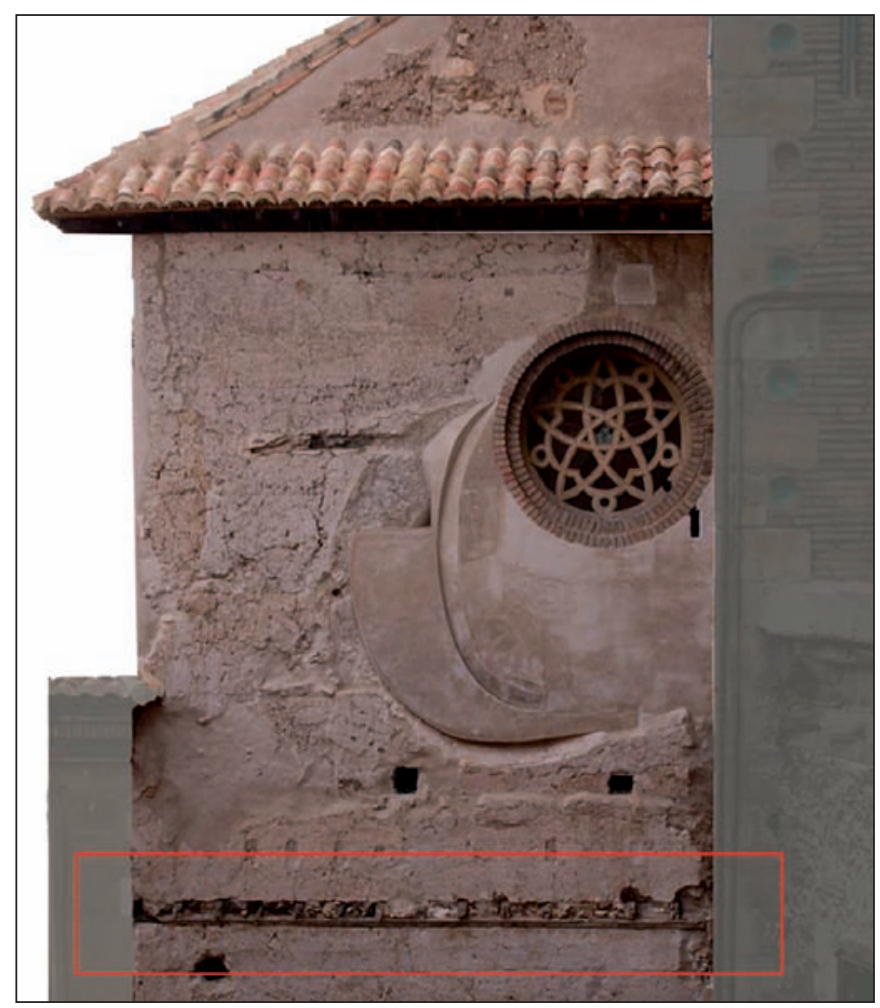

Fig. 33 Alero mutilado hallado en el muro hastial

este par (76C) y otra de un canecillo del alero primitivo (11 HP). Los resultados indican que el par y el canecillo del hastial son de la misma época (1040-1220 cal AD), sin embargo, el canecillo de la cubierta actual data de unos 100 años más tarde ${ }^{24}$. Cifras al margen, lo importante es que dos de las muestras son iguales y una tercera es distinta y posterior. Ciertamente, si el proceso de ejecución de la cubierta primitiva era el mismo de la que la que existe hoy, los canecillos estarían embebidos en el muro, por lo que su reutilización sería inviable.

A partir del estudio de la entrega tanto exterior como interior de la techumbre al muro, se han podido establecer dos hipótesis de montaje. Se descubrió que el macizado tras el alicer no corresponde a la intervención del servicio de Regiones Devastadas entre 1940 y 1953, sino que es anterior a 1335. En cuanto al origen de la techumbre, se encontraron indicios que permiten contemplar la posibilidad de que la techumbre que existe hoy pudo montarse reutilizando piezas de una anterior. Esto explicaría la existencia de diferentes técnicas pictóricas, diferentes tipologías de un mismo elemento estructural y la aparición de piezas claramente reutilizadas.

\footnotetext{
${ }^{24}$ Edades calibradas
} 
Sustentando a la techumbre y eclipsados por ella, los muros de la catedral de Teruel guardan recelosos un pasado que descifra pasajes de la historia y épocas de su ciudad. Construidos, reconstruidos, disfrazados y mutilados, han podido soportar el peso de la antigüedad. El estudio de los muros y de su encuentro con la techumbre de la catedral de Santa María de Mediavilla de Teruel ha encontrado respuestas a ciertas incógnitas históricas, al mismo tiempo que ha tropezado con nuevos interrogantes y líneas de interpretación, que se acercan más a la realidad constructiva de este magnífico monumento.

\section{Bibliografía}

Almagro Gorbea, A., 1991: Arquitectura mudéjar de Teruel, en Borrás Gualis G.M. (coord.), Teruel mudéjar, Patrimonio de la Humanidad, pp. 157-200. Zaragoza, Ibercaja.

Andrés Rubio, J., 2000: Plan Director de la Catedral. Teruel.

Andrés Rubio, J., 2003: Proyecto Obras de Restauración de las Cubiertas Superiores y Cimborrio de la Catedral de Teruel. Teruel, Cabildo de la S.I. Catedral de Teruel y Obispado de Teruel y Albarracín.

Blasco y Val, C., 1870: Historia de Teruel, pp. 119-129. Teruel, Imprenta J. Alpuente.

Borrás Gualis, G. M., 1999: La Techumbre de la Catedral del Teruel. Zaragoza, Diputación General de Aragón, Ministerio de Educación y Ciencia y Caja de Ahorros de la Inmaculada de Zaragoza.

Cabré Aguiló, J., 1909-1910: Catálogo Artístico-Monumental de la provincia de Teruel.

Cristini, V., Mileto. C. y Vegas, F., 2009: Reinforcement of rammed earth constructions with gypsum in Aragon area, Spain. Mediterra 2009 - 1st
Mediterranean Conference on Earth Architecture, pp. 99-108. Cagliari. Escola Superior Gallaecia, Craterre Ensag.

Guinzburg, C., 1994: Mitos, emblemas e indicios: morfología e historia. Barcelona, Gedisa.

Harris, E. C., 1991: Principios de estratigrafía arqueológica, Barcelona, Crítica.

Ibáñez González, J., 2002: Informe Arqueológico del Plan Director de la Catedral de Teruel. Teruel.

Ibáñez González, J., 2009: Informe de la intervención arqueológica realizada en la cubierta de la Catedral de Santa María de Mediavilla, Exp. 400/2008. Teruel.

Marqués de Monsalud, 1907: Informe para la Comisión Nacional de Turismo. Madrid.

Mileto, C., 2000: Algunas reflexiones sobre el análisis estratigráfico de fábricas, Loggia. Arquitectura \& restauración, 9, pp. 80-93.

Moralejo Álvarez, S., 1986: Modelo, copia y originalidad, en el marco de las relaciones artísticas hispano-francesas (siglos XI-XIII) Actas. V Congreso Español de Historia del Arte, Barcelona 1984, p. 104 vol.1. Barcelona.

Navarro Aranda, M., 1953: La arquitectura cristiano mudéjar de Teruel, pp. $177-$ 183. Teruel.

Novella, A.; Rabanaque, E.; Sebastián, S. y Yarza, J., 1999: El Artesonado de la Catedral de Teruel. Teruel. IberCaja.

Pano y Ruata, M., 1904: La techumbre de la catedral de Teruel, Aragón, 5, pp. 53-59, 103-108, 152-157, 214-217, 304-308 y 475-478.

Tomás Laguía, C., 1953: Catalogo de pergaminos y documentos insertos en ellos, existentes en el Archivo de la S.I. Catedral de Teruel. Teruel.

Torres Balbás, L., 1953: La Iglesia de Santa María de Mediavilla, Catedral de Teruel, Archivo Español de Arte, 102.

Yarza Luaces, J., 1981: En torno a las pinturas de la techumbre de la catedral de Teruel, Primer Simposio Internacional de Mudejarismo, pp. 41-70. MadridTeruel. Consejo Superior de Investigaciones Científicas.

Recibido: 21 de marzo de 2011 Aceptado: 1 de agosto de 2011 